\title{
Mind the Gap: \\ Capturing Value from Basic Research through \\ Combining Mobile Inventors and Partnerships*
}

\author{
Bruno Cassiman \\ IESE Business School and KU Leuven \\ bcassiman@iese.edu \\ Reinhilde Veugelers \\ KU Leuven, Bruegel and CEPR \\ reinhilde.veugelers@kuleuven.be \\ Sam Arts \\ KU Leuven \\ sam.arts@kuleuven.be
}

This version August 2017

First Version: October 2009

\begin{abstract}
To successfully generate more valuable technologies from accessing basic research knowledge, firms need to combine institutional and individual level bridges to universities and research institutes active in basic research. This combination is particularly important when the new technology builds on scientific prior art. While mobile inventors are needed to transfer and translate basic knowledge into new technologies, partnerships provide the commitment, resources and incentive structure to integrate this basic research knowledge more effectively into the firm's innovation process, thus improving the value capture from mobile inventors. Our findings in the micro-electronics field illustrate the importance of jointly accounting for firm and inventor level industry-science links to assess their effectiveness and provides evidence on complementarity from using both. Furthermore, identifying the scientific nature of the technology projects critically determines whether the combination of these links allow to capture more value.
\end{abstract}

Key words: basic research, inventor, partnership, complementarity, industry-science links

\footnotetext{
* The authors wish to thank Ajay Agrawal, Massimo Colombo, Dirk Czarnitzki, Lee Fleming, Alfonso Gambardella, Rahul Kapoor, Andy King, Lori Rosenkopf, Jasjit Singh, Jason Snyder, Marco Tortoriello, Giovanni Valentini, Bruno Van Pottelsberghe, Rosemarie and Arvids Ziedonis and the seminar participants at HBS, Wharton, Michigan, Toronto, UCLA, USC, Bocconi, Politecnico di Milano, LMU Munich, HEC Paris, INSEAD, University of Zurich; MOVE, Alma Graduate School Bologna, ZEW, EARIE, EPIP, ICMIT and REER conferences for useful comments; Andre Clerix, Johan Van Helleputte and IMEC for the collaboration and data. Best Paper Award received at the $6^{\text {th }}$ IEEA-ICMIT 2012 Conference. Bruno Cassiman is a research fellow of the SP-SP Research Center at IESE Business School and acknowledges partial financial support from the Spanish Ministry of Science and Innovation through project $\mathrm{n}^{\circ}$ ECO2009-13169 and ECO2015-71173-P, the Catalan Government Grant n ${ }^{\circ}$ 2009-SGR919 and Fundación Ramon Areces. Financial support of the Science Foundation Flanders (FWO) and the Research Council of KULeuven is gratefully acknowledged (GOA/12/003, G.0825.12, G071417N). We are also grateful to ECOOM (Policy Research Center for R\&D Monitoring) for providing us access to the patent data.
} 


\section{Introduction}

Since Nelson asked his famous question "Why do firms do basic research?" much has been written on the subject (Nelson, 1959). More recently access to basic research rather than internally developing basic research has received more attention within the firm's innovation strategy (Arora et al. 2018). Firms collaborate with universities or research centers to access basic research and integrate these insights into their own research efforts and generate superior performance outcomes (Belderbos et al. 2004).

In this paper we argue that successfully accessing basic research requires complementary actions by the firm. On the one hand, basic research knowledge is transferred through individuals. A proper translation and integration of this knowledge into the innovation process of the firm requires the involvement of individuals familiar with this knowledge (Jensen \& Thursby 2001). This holds the more so for scientific knowledge that is more complex and early stage (Zucker et al. 2002, Agarwal 2006). Moreover, scientific knowledge and technology are developed within different communities requiring bridging these communities by individuals that foster this translation (Dasgupta and David 1994; Allen 1998; Gittelman and Kogut 2003).

On the other hand, the firm needs to commit to a strategy of accessing basic research. Such a commitment signals the organization's willingness to integrate this knowledge in the firm's innovation process and leverages resources within the organization for this purpose. Partnerships and institutional collaborative agreements are a vehicle for establishing such commitment (Brandstetter and Sakakibara 1998, Henderson and Cockburn 1998, Veugelers and Cassiman 2005).

In this paper we provide evidence for both of these channels, institutional and individual, to effectively access basic research for firms. Our major contribution is to argue and provide evidence that both channels are complementary. The involvement in both complementary channels directly affects the integration and translation of the basic research into more applied technologies that are closer to commercialization. Firms that are committed through a partnership with institutions active in basic research can benefit more from including individuals familiar with the research performed at these institutions in the internal research projects at the firm. At the same time, such a partnership indicates a commitment to resources and provides incentives that affect the engagement of researchers in its internal research projects and generate better results. Especially when the knowledge is science-based, we argue that accessing basic research through different channels simultaneously, improves outcomes.

To empirically demonstrate this complementarity between different channels for accessing basic research, we need to simultaneously observe different bridging mechanisms that can affect the outcome of technology development by the firm. And we need a reasonable counterfactual for the different alternatives for generating this new technology. We exploit a specific setting in the microelectronics and semiconductor industry where a research institute's intellectual property management system allows us to identify and trace technologies developed by partner and non-partner firms and 
where some technologies also have the involvement of individuals familiar with the research developed at the research institute.

Our empirical results support the complementarity between institutional and individual level links for science based inventions. We find that firms that combine a partnership with the use of individuals that were active at the research institute develop patents that receive more forward citations. These individuals are an important mechanism for bridging the gap with basic research, but only when used in combination with a partnership. Poaching of these individuals by firms without a partnership link to the research institute are less successful in developing related technologies. Likewise, firms with an institutional partnership who do not consummate their partnership by having individuals formerly active in the research institute in their technology development teams are not capturing any extra value from their partnership when developing those technologies. Interestingly, we find that this complementarity only holds for projects with an important scientific component: individual inventors only support the creation of valuable technologies for those projects at partner firms that rely on scientific prior art.

In order to establish the most successful routes to access basic research, our empirical methodology needs to deal with several selection issues. Do the best firms, most apt to effectively access basic research, select into an institutional partnership with a research institute? Do the best inventors, most apt to bridge scientific and technology communities, get targeted? Unfortunately, the setting where we apply our methodology does not provide clear exogenous variation to pin down the causal effects of partnering and using inventors formerly active at the research institute. Nevertheless, as we examine the effects at the invention level, we are able to compare which technologies are more successfully developed within partner firms, controlling for company and inventor characteristics potentially driving selection. Moreover, we look at different cuts of the data to examine potential inventor selection issues. In the end we cannot eliminate all uncertainty about the actual mechanisms at work, but we believe that our findings provide sufficient support to advocate for future research to look at the portfolio of bridging mechanisms and the nature of the technological inventions when analyzing the effect of firms relying on basic research in other settings. While our findings are derived from the analysis of the interaction with a particular research organization focusing on basic research in microelectronics and semiconductors, the methodology developed is sufficiently generic so that it can be applied in other settings to test the robustness of our findings.

In the following section, we discuss the gaps in the literature and develop empirical predictions related to how firms effectively appropriate returns from accessing basic research in their innovation process. Section 3 discusses our empirical setting. Section 4 elaborates on our data development and methods while Section 5 presents our results. Section 6 concludes with some caveats and directions for further research.

\section{Accessing basic research}




\subsection{Why firms want to access basic research?}

Any explanation for why firms want to tap into basic research needs to argue that ultimately basic research enhances firm performance (Nelson 1959, Evenson and Kislev 1976, Cassiman, PerezCastrillo and Veugelers 2002). Basic knowledge leads to a better identification, absorption and integration of external (public) knowledge (Cohen and Levinthal 1989, Gambardella 1995, Cassiman and Veugelers 2006). Faster identification, absorption and integration of external knowledge in turn leads to increased productivity of the applied research process, resulting in more valuable technologies (Fabrizio 2009, Laursen and Salter 2006). This process of integration requires firms to develop the initially acquired basic knowledge further into new technologies and eventually into products and processes. In addition, Fleming and Sorenson (2004) argue that scientific knowledge serves as a map for technological search, guiding research towards the most promising technological directions, thereby avoiding wasteful experimentation. Moreover, basic knowledge can simultaneously fertilize different research projects (Henderson and Cockburn 1996).

Fleming and Sorenson (2004) find that patents which rely on scientific prior art are more valuable as measured by forward citations, particularly in case of more complex and interdependent lines of technology. Consistent with these results, Cassiman et al. (2008) find that firms that actively engage in scientific research develop patents that receive more forward citations. As a result, access to science-based basic research can enhance the innovation performance of the firm by increasing the average value of the new technologies.

\subsection{The difficulty of accessing basic research}

While firms can derive benefits from accessing basic research in their innovation process, there are three key reasons why they may encounter difficulties in doing so. First, basic research is experimental or theoretical work undertaken primarily to acquire new knowledge without any particular application or use in view (OECD 2002). It is typically conducted in institutional settings other than firms, i.e. in organizations like universities and basic research organizations. Aghion et al. (2009) show that universities have a larger incentive to engage in early stage basic research with uncertain commercial returns. Firms are only willing to step in closer to commercialization. By outsourcing more basic R\&D projects to universities, rather than developing them in-house, firms provide a credible commitment not to abort or alter projects with a more basic character and less certain commercial outcomes (Lacetera 2009). Such a commitment through outsourcing provides the right incentives for the researchers involved to invest effort in these research projects. But at the same time, the difference in the institutional environment where these types of projects are embedded complicates the further development by the firm of basic research into new technologies because firms have to cross this institutional divide (Gittelman and Kogut 2003).

Second, basic research at the frontier of knowledge is often complex, early stage, and not yet fully codified (Zucker et al. 2002, Bechky 2003, Agrawal 2006). As Bessen (2011) argues, the 
tacitness of basic knowledge is, at least partly, endogenous. Organizations will only cover the cost of codifying knowledge whenever the benefit is sufficiently high. Hence, as basic research involves early stage technologies with returns that are hard to identify and appropriate, we can expect basic research knowledge to be less codified and more difficult to transfer. The probability of encountering more tacit knowledge increases with the scientific content of this basic knowledge given the low incentive in the scientific community to technically codify all background knowledge beyond scientific publications.

Ensuring the correct translation of this complex and more tacit basic knowledge into valuable new technology requires the involvement of community-spanning inventors who move between scientific and technological communities (Zucker et al. 2002, Gittelman and Kogut 2003). This involvement is critical because such complex knowledge typically must be modified to function in new applied contexts. Moreover, the translation and integration of this basic knowledge requires additional investments by the company (Jensen and Thursby 2001, Tsai 2001, Foray and Lissoni 2010). When knowledge stocks have different, interdependent dimensions, firms require a proper internal configuration to bridge for innovative success (Cassiman and Veugelers 2006, Tzabbar et al. 2008, Tzabbar et al. 2013). Firms need to create a stimulating environment, provide resources, and put the right incentives in place for their researchers to link to the scientific community.

But the incentives for the firm to invest in building this basic research absorption capacity are muted by the public good nature of basic research which generates spillovers to others. As these spillovers increase with the scientific content of the knowledge, an important commitment is required for firms engaging in this type of basic research. In addition, Kotha et al. (2013) show that the transfer and commercialization of knowledge from university research entails important coordination costs that increase with the scientific content of the knowledge and reduce the likelihood of licensing the technology to firms. As a result, firms need to commit to make specific investments to capture value from these relationships.

\subsection{How to access basic research?}

To address the challenges of accessing basic research the literature has discussed the role of two different bridging mechanisms: inventor mobility at the individual level and cross-institutional cooperation at the organizational level.

Inventor mobility. By now, a substantial literature has studied inventor mobility as a critical mechanism to transfer knowledge across organizational or institutional boundaries. Most of this research is concentrated on the mobility of inventors between firms (e.g. Hoisl 2007 and 2009). By and large, this literature confirms the importance of inter-firm mobility of inventors as a pathway for knowledge transfer. Almeida and Kogut (1999) show how inter-firm mobility of inventors is an important driver of local externalities in the semiconductor industry in the US. Tracing the patenting 
activities of inventors, different studies find support for learning-by-hiring (Song, Almeida and Wu 2003; Singh and Agrawal 2011). By showing that mobile researchers have better access to resources and networks, Cañibano, Otamendi and Andujar (2008) provide further insights into why mobile researchers are interesting conduits for knowledge transfers.

Little empirical work has examined inventor mobility between scientific and technology communities, such as between universities or public research organizations and firms (Allen 1977, Tushman and Scanlon 1981, Breschi and Catalini 2010). Ejsing et al. (2013) for example finds in matched Danish employer-employee data that newly hired university scientists contribute more to a firm's patenting than newly hired recent graduates or recruitments from other firms. Furthermore, corporate inventors who co-publish with universities or public research organizations generate more valuable patents, confirming the importance of their boundary spanning role (Gittelman and Kogut 2003, Fabrizio 2009). Firms who have ties with academic star scientists are found to develop more and more valuable patents (Henderson and Cockburn 1996, Zucker et al. 2002, Cockburn and Henderson 1998).

Cross-institutional cooperation. The most widely studied mechanism to access basic research are partnerships between firms and universities or public research organizations (Audretsch and Stephan 1996, Zucker et al. 1998, Cockburn and Henderson 1998, Brandstetter and Sakakibara 1998). Formal partnerships have been shown in theory models to lead to improved incentives for investment in R\&D and absorptive capacity, particularly when they can improve the appropriation of innovation results (d'Aspremont and Jacquemin 1988, Kamien and Zhang 1992). Most prior research studies inter-firm cooperation among firms, and illustrate that $R \& D$ alliances increase the rate of knowledge integration (Tzabbar et al. 2013). In contrast, R\&D cooperation between public research organizations or universities and industry involves less appropriation concerns. But as it involves early stage basic research, it is characterised by high uncertainty, high spillovers to other market actors, high information asymmetries between partners, and therefore high transaction costs for knowledge exchanges (Veugelers and Cassiman 2005; Kotha et al. 2013). Empirical evidence confirms that only few firms cooperate with universities (Veugelers and Cassiman 2005). Nonetheless, those firms are found to enjoy a higher innovation productivity and higher sales from innovative products (Belderbos et al. 2004, Belderbos et al. 2006).

\subsection{Complementary bridging mechanisms to access basic research}

While the existing empirical analyses typically find a positive relation between cross-institutional partnerships and innovation performance of firms, they leave out the role of the actual micro-level mechanisms and the individual researchers that link basic research to innovation performance. At the same time, the studies on researcher mobility typically do not control for organization level connections 
of the firms such as partnership agreements that involve considerable commitment to collaborative research.

We argue that these different bridging mechanisms cannot be analyzed in isolation. First, as the preceding discussion shows, different mechanisms positively affect the innovation performance of the firms, but these mechanisms are likely positively correlated. Establishing the effect of one of these mechanisms on the firm's innovation performance requires controlling for the alternative mechanisms.

Second, and more importantly, we argue that these different bridging mechanisms are actually complementary. Accessing basic research by firms involves a fundamental coordination problem between the locus and content of basic research performed at universities by individual researchers on the one hand, and technology development and eventual commercialization performed in the innovation process at firms on the other hand (Aghion et al., 2009; Lacetera, 2009). This coordination problem is even more apparent the more early stage, tacit and uncodified the basic research still is.

Partnerships with research institutes are an important commitment device to address this coordination problem. Particularly science-based research projects by the firm, as these are longer term, benefit from having a more long term vision and commitment. Partnerships with research institutions come with considerable investment of resources. A partnership is akin to an ownership stake in the outcome of the research projects at the research institute. As a result of such an ownership stake, firms have more incentives to invest more effort in developing technologies based on this relationship (Aghion and Tirole, 1994). They have higher incentives to build up capacity to absorb and integrate external knowledge sourced from the research institute. As a result, the commitment provided by an institutional partnership at the same time increases the benefit from establishing an inventor link with the research institute. With a higher incentive and capacity to absorb technologies sourced from the research institute, firms with institutional links will be able to reap more benefits from attracting an inventor active in the research institute. Inventor links can benefit from the resources invested by the firm in the relationship, the incentives to integrate external knowledge and the exposure to information and new ideas that these partnerships provide.

At the same time, the commitment from the partnering firm to integrate knowledge from the research institute into the firm's innovation process, increases the incentive of inventors with relevant knowledge to connect with the firm's knowledge base. For example, inventors that join the firm from the research institute are more likely to take up leading positions in the firm on applied research projects that build further on the basic research from the research institute. This increases the likelihood that other inventors from the research institute integrate their knowledge.

Finally, the partnership exposes the firm early-on to new ideas and research directions. Firms will be better able to spot, attract, and accommodate those mobile inventors that best fit the organization. The partnership link induces a network of relationships that provides evaluation and information on inventors within the field. For example, Leonard-Barton (1984) found that $84 \%$ of technical talent of 
firms was reported to be found through network contacts rather than formal employment and job search procedures (Ahuja et al. 2008).

Following these arguments, we will examine the interaction between firm and inventor level mechanisms to access basic research, looking for a possible complementarity between both types of links at the invention level. We expect that mobile inventors positively affect the value of the firm's technologies more so when they are embedded in firms with partner links. We expect that this complementarity will matter especially for more science-related R\&D projects. Because the necessary background knowledge to translate findings from early stage scientific research into valuable technology is typically complex and not fully codified, "strong" ties are needed (Hanssen (1999). Combining partner and inventor links increases the "strength" of each of these bridging mechanisms.

\section{Research setting: micro-electronics and IMEC}

Our empirical predictions on the complementarity between partnership and inventor links are tested in the empirical setting of the micro-electronics field. We examine the links of firms in this field to basic research performed at IMEC - the Interuniversity Microelectronics Centre - a world class institute with an explicit mission to bridge the gap between basic research developed at universities and applied research developed in industry. ${ }^{1}$ This research setting and IMEC's unique business model allow us to carefully identify and disentangle the effects of inventor mobility and partnerships.

\subsection{Links to basic research in the micro-electronics industry}

The micro-electronics industry is an interesting environment given the close relationship between science and technology (Meyer-Krahmer and Schmoch 1998). First, basic research is often at the forefront of breakthroughs in micro-electronics. For this reason, companies are seeking to cooperate with universities and research institutes to tap into emerging research opportunities as early as possible. Second, knowledge sharing via researcher interaction and mobility between firms and research organizations has been shown to be an important mechanism to bridge this gap in microelectronics (Meyer-Krahmer and Schmoch 1998, Almeida and Kogut 1999). Moreover, learning-byhiring is considered as a key driver of the rapid growth of the semiconductor industry in the United States (Rogers and Larson 1984).

\footnotetext{
${ }^{1}$ We use the terminology to identify basic and applied research developed in the OECD Frascati manual (2002): Basic research is experimental or theoretical work undertaken primarily to acquire new knowledge of the underlying foundations of phenomena and observable facts, without yet any particular application or use in view. Applied research is original investigation undertaken in order to acquire new knowledge. It is, however, directed primarily towards a specific practical aim or objective.
} 


\subsection{IMEC as link to basic research}

IMEC was founded in 1982 by the regional Flemish government in Belgium as a non-profit organization with the mission to be a world leader in basic research in micro-electronics. The center's involvement in the scientific community is illustrated by its close collaboration with world-class universities and by the presence of pre-and post-doctoral researchers from universities and public research centers from all over the world at its laboratories. The numerous conference participations and top publications from its researchers have consolidated its scientific reputation. ${ }^{2}$

At the same time, IMEC is closely connected to industry. The board of directors includes delegates from the industry who stipulate IMEC's strategic roadmap which is focused on precompetitive application-oriented technologies three to ten years ahead of industrial needs. IMEC has attracted leading global firms such as Intel, Samsung, Texas Instruments, Micron, NXP, Hynix, Elpida, Infineon, Panasonic, TSMC, Sony, Qualcomm and ST Microelectronics willing to pay hefty fees of several millions of dollars per year to be a partner. Together with IBM in Albany in the US, IMEC in Leuven has become one of the two most important centers for nano-electronic research with an important focus on process technologies. ${ }^{3}$

\subsection{IMEC’s business model}

In order to realize its mission as bridging institution between universities and industry, IMEC implements a unique business model which stimulates the interaction between basic and industrial researchers, facilitating the cross-fertilization of knowledge. By financially contributing, firms can become an IMEC partner. Firms joining IMEC's Industrial Affiliation Program get a "seat at the table" and set the research agendas. A partner firm can send researchers to collaborate in the programs in which the firm participates, giving them also a "spot in the lab". ${ }^{4}$ Around 15 different industrial affiliation programs were running in 2010, of which a large majority in the Process Technology Unit, focused on the next generation of semiconductors. Guest researchers, including academic and industrial researchers affiliated to one of its partners, conduct research at the IMEC laboratories in close collaboration with other researchers. Besides IMEC's own research personnel (about 1,000), more than 520 guest researchers with 60 different nationalities were conducting research at IMEC's laboratories in 2010, including 344 visiting industrial researchers.

\footnotetext{
${ }^{2}$ Around the time of the analysis in 2010, IMEC was collaborating with approximately 200 universities worldwide in its core CMOS (Complementary Metal Oxide Semiconductor) division only and hosted 194 visiting PhD students at its research facilities. IMEC's own researchers (around 1,000) published more than 1,750 scientific articles in 2009.

${ }^{3}$ The IBM partnership has no formally distinguishable form as is the case for IMEC. As a result, the data cannot be generated in a similar way for the IBM case to provide a direct empirical comparison of both institutions.

${ }^{4}$ We thank Rosemarie Ziedonis for suggesting this use of language.
} 
Crucial for its business model is an aligned Intellectual Property (IP)-strategy so that all collaborating partners are able to build their own and unique IP-portfolio on top of shared IP. IMEC has elaborated an IP-strategy to stimulate this technology development and to limit blocking amongst its corporate partners (Van Helleputte and Reid 2004). The basic platform technologies are accessible to all its partners. These technologies, developed by IMEC or by IMEC in collaboration with partners, are still in a pre-competitive phase and require additional $R \& D$ to turn them into commercial technologies. The patents covering these platform technologies are all owned by IMEC. All technology developed at the IMEC laboratories, in execution of dedicated programs by academic or industrial researchers, is contractually co-owned by IMEC. Partners gain access to these technologies, as far as needed for the exploitation of the program, via a non-exclusive and non-transferable license. Corporate partners can build on these technologies to develop proprietary IP in line with their own commercial needs. Technologies which result from proprietary research activities by a partner are assigned exclusively to that partner. These technologies, where IMEC takes no ownership position, represents the area where partners can capture the return on their investment in IMEC.

\section{Data and methods}

\subsection{Data and sample}

As our source sample we collected all patent applications filed by IMEC between 1990 and 2005, which we retrieved from the Worldwide Patent Statistical Database. This set of patents was validated by IMEC. ${ }^{5}$ From this source sample of 578 IMEC patents, we identified 531 unique inventors. These inventors, which we label as IMEC inventors, were certified by IMEC as having been actively involved in the research projects conducted in IMEC's facilities. ${ }^{6}$

Next, we retrieved all subsequent US patents in the complete patent database listing at least one of these IMEC inventors. ${ }^{7}$ From this sample of subsequent US patents, we then identified all company-assigned patents where the IMEC inventor was not working at IMEC anymore at the time of application. We name the IMEC inventors listed on these patents mobile inventors. These mobile inventors have formerly been active as an IMEC inventor in the generation of IP at IMEC but are not

\footnotetext{
${ }^{5}$ These patents include 281 EPO, 255 USPTO and 42 PCT patent applications

${ }^{6}$ Inventors listed on patents have contributed to the invention but do not necessarily have any legal right to the invention. Note that given the structure of the IMEC programs these IMEC inventors are not all formal IMEC employees as IMEC hosts many different types of researchers beyond IMEC employees: post-docs, doctoral students, master students, academic faculty from universities worldwide as well as visiting researchers from affiliate partners.

${ }^{7}$ All different name variants and corresponding person identification numbers of this set of inventors were retrieved using search keys to take into account different spellings. The match of inventor names was made based on matches of name, first name, initial and address. In the case of differences in addresses or names, we checked the technology field of the patent and the applicant name to determine a match. While this rigorous approach might lead to false negative matches, it minimizes/eliminates false positive matches. Given our objective to trace inventor interaction and mobility, this conservative approach seems more appropriate.
} 
working at IMEC anymore at the time of patenting this subsequent company-assigned patent, which implies mobility took place from IMEC to the patenting firm. ${ }^{8}$ Finally, we collected all companyassigned US patents citing our source sample of 578 original patents owned by IMEC.

In a next step, we matched the applicants on all these US patents to the list of IMEC partners, i.e. corporate members of IMEC's Industrial Affiliation Program. After cleaning, ${ }^{9}$ our final sample consists of 1,089 company-owned USPTO patents filed between 1990 and 2005 - 221 patents with a mobile inventor and 868 patents citing the original set of patents owned by IMEC. ${ }^{10}$ We have 87 companies in our sample, of which 33 are IMEC partners. $56 \%$ of our 1,089 patents are developed by an IMEC partner. We have 1,835 unique inventors of which 57 are mobile inventors. $20 \%$ of our 1,089 patents are developed by a mobile inventor.

\subsection{Empirical model}

In our final sample of company-owned patents we can estimate the effect of different mechanisms to bridge the gap with basic research on the value of the patents. In line with prior research studying the effect of links with science on technological innovation (e.g., Fleming and Sorenson, 2004; Cassiman, Veugelers, and Zuniga, 2008), we use forward citations to measure patent value, and count the number of forward citations received from subsequent patents within 5 years after application. These forward citations are corrected for citations across patent families. The number of forward citations is a commonly used proxy for the technological impact and economic value of inventions (Trajtenberg 1990, Harhoff et al. 1999, Gambardella et al. 2008). ${ }^{11}$ To estimate the number of forward citations, we

\footnotetext{
${ }^{8}$ IMEC has a database with all researchers which have been working at IMEC for at least one month (own personnel as well as visitors). As such, we can verify whether an inventor indeed worked at IMEC at some point in time and left. Not all inventors in our sample were found in the database. For those which were potential mobile inventors, we conducted a web search to find additional information on their employment. When inventors were working for the assignee company at the time of patenting, we treated them as mobile inventors while those for which we did not find information on their affiliation or who were not working for the assignee company were excluded from further analysis.

${ }^{9}$ We restrict attention to USPTO patents only $(3,606)$ as patents from the USPTO and EPO offices may not be comparable, and because disambiguated inventor information is only available for US patents (Li et al., 2014). Moreover, the patent attorney of IMEC mentioned that they tend to file for USPTO patents first at it relates to their main market and the procedure is faster and cheaper. We also exclude patents (co)assigned to IMEC (302), as these do not reflect the proprietary IP of the partner. Further excluded are patents not assigned to companies (488), patents from companies with less than 4 patents in our sample (502), patents which do not share the same technological space (Fraunhofer 30 technology fields) as the IMEC patents (65), patents assigned to mobile inventors before they were at IMEC (288), patents for which we don't have all relevant characteristics (e.g. assignee information (546) or on the affiliation of the mobile inventors (326). Note also that the set of 578 original patents owned by IMEC are only used to generate the sample of company-owned patents, but are not included in the analysis.

${ }^{10}$ These Citing Patents are necessarily developed after the background technology of IMEC has been developed. Similarly, patents with mobile inventors have been developed after the inventor passed through IMEC.

${ }^{11}$ In unreported results we also measured patent value by the fact that a patent is in the top $5 \%$ of the citation distribution. Results are consistent with those reported using citation counts.
} 
use Poisson quasi-maximum likelihood models (PQML). ${ }^{12}$ PQML renders consistent estimates under correct mean specification and is robust to a large number of zero's and to overdispersion of the dependent variable (Gourieroux, Monfort, and Trognon 1984; Silva and Tenreyro 2006). We cluster standard errors at the firm level across all models.

To estimate the impact of mobile inventors and/or firm partnerships at the patent level, we define two key characteristics of our sample of patents:

- Inventor $\operatorname{link}_{i f}(\in\{0,1\})$ indicates that patent $i$ of firm $f$ has a mobile inventor

- Partner $\operatorname{link}_{i f}(\in\{0,1\})$ indicates that patent $i$ is assigned to an IMEC partner firm, i.e. firm $f$ has an institutional link with IMEC.

Based on these two key characteristics, we define four mutually exclusive types of patents:

- Inventor Partner P $_{i f}(\in\{0,1\})$ indicates whether or not patent $i$ of firm $f$ has a mobile inventor and firm $\mathrm{f}$ is an IMEC partner.

- Inventor NoPartner $i f(\in\{0,1\})$ indicates whether or not patent $i$ of firm $f$ has a mobile inventor while firm $f$ is not an IMEC partner.

- NoInventor Partner $_{i f}(\in\{0,1\})$ indicates whether or not patent $i$ of firm $f$ does not have a mobile inventor while firm $f$ is an IMEC partner.

- NoInventor NoPartner $i f(\in\{0,1\})$ indicates whether or not patent $i$ of firm $f$ does not have a mobile inventor and firm $f$ is not an IMEC partner.

The classification of the patents according to this methodology allows us to estimate the impact of mobile inventors - a spot in the lab - or, firm partnerships - a seat at the table - and the combination of both bridges.

While patents that share an IMEC inventor can be considered to be in the relevant technology space, the NoInventorPartner patents could include patents from partner firms which are in unrelated areas, as many of the partner firms are large diversified firms. We therefore restrict patents in this category to those citing at least one of the IMEC owned patents in our source sample. Similarly for the NoInventorNoPartner category, we only include those patents that cite at least one of the IMEC owned patents from the source sample. These citing patents are filed after the IMEC patents from the source sample, share the same technology space and therefore provide a reasonable control group. Note that in contrast to some of the literature, we do not use the citation by a company-owned patent

${ }^{12}$ Our findings are robust if we use negative binomial models (see footnote 22). 
to IMEC technology to trace an explicit knowledge flow. We use citations only for identifying patents that are related in technology space and, hence, provide a tight control on the type of technologies considered. ${ }^{13}$ As a robustness check, we also consider a more common control group of patents of the same application year and within the same technology class (see section 5.3).

To test whether links matter more for projects that rely on scientific knowledge as prior art, we construct a binary variable Science. Science equals one in case the patent cites at least one scientific publication as prior art. We do not take Science as a measure of knowledge flow directly related to the cited scientific publication, but rather as a measure of the importance of complex and scientific background knowledge for a particular project. ${ }^{14}$ We make use of an automated algorithm which matches non-patent references to Web of Science publications (Callaert et al. 2012). We split the patents in each of the 4 exclusive categories into those who score on Science versus those that do not. For example, the Inventor Partner category is split into

- Inventor Partner Science if $_{(}(\in\{0,1\})$ indicates whether or not patent $i$ cites at least one scientific publication, has a mobile inventor and firm $f$ is an IMEC partner.

- Inventor Partner NoScience $i f(\in\{0,1\})$ indicates whether or not patent $i$ does not cite any scientific publication, but has a mobile inventor and firm $f$ is an IMEC partner.

With $V_{i f k(t)}$ our dependent variable measuring the number of forward citations of patent $i$ of firm $f$ of technology class $k$ applied for at time $t$, our main regressions takes the following form:

$$
\begin{aligned}
& V_{i f k}=\alpha+\theta_{\text {ip }} \text { Inventor Partner }_{i f k}+\theta_{\text {nip }} \text { NoInventorPartner }_{i f k} \\
& +\theta_{\text {inp }} \text { Inventor NoPartner }{ }_{i f k}+\theta_{\text {ninp }} \text { NoInventorNoPartner }_{i f k} \\
& +\beta_{i} P_{i f k}+\gamma_{F} F_{f(t)}+\tau_{k}+\mu_{t}+\epsilon_{i f k}
\end{aligned}
$$

Where

$$
P_{i f k}=\text { Patent level control variables }
$$

\footnotetext{
${ }^{13}$ Note that the patents with a mobile inventor do not necessarily cite any of the IMEC patents. But they have an inventor in common with at least one of these patents.

${ }^{14}$ Using a survey targeted at R\&D managers, Roach and Cohen (2013) find that patent references to scientific publications provide a good measure for the extent to which the particular R\&D projects relied on scientific research from universities and public research organizations. We are unable to identify inventor-given citations to scientific publications given that the distinction between examiner and inventor-given citations is only available for patents granted since 2001. Nevertheless, while prior studies illustrate that more than $40 \%$ of patent references are introduced by patent examiners (Alcacer and Gittelman 2006, Alcacer et al. 2009), less than 10\% of nonpatent references are inserted by examiners (Lemley and Sampat 2012). As such, any possible bias introduced by examiner-given citations should be limited.
} 


$$
\begin{aligned}
& F_{f(t)}=\text { Firm }- \text { year level control variables } \\
& \tau_{k}=\text { Technology Field Fixed Effects } \\
& \mu_{t}=\text { Year Fixed Effects }
\end{aligned}
$$

The $\theta_{\mathrm{x}}$ are our key parameters of interest in the regressions. Earlier work would suggest that either partner link or mobile inventor links affect $V_{\text {ifk. }}$. Our empirical model allows for a more refined test by analyzing the complementarity between partner and inventor links. With NoInventorNoPartner our excluded category, we would expect the InventorPartner patents to have a significantly positive coefficient, but also a coefficient higher than those patents that would only use one link, i.e. either the InventorNoPartner or the NoInventorPartner patents:

$$
\theta_{\text {ip }}>\theta_{\text {ninp }} ; \theta_{\text {ip }}>\theta_{\text {inp }} ; \theta_{\text {ip }}>\theta_{\text {nip }}
$$

We also check whether the effect of a mobile inventor link will be stronger for a partner firm than for a non-partner firm, which is an explicit test for complementarity: ${ }^{15}$

$$
\theta_{i p}-\theta_{\text {nip }}>\theta_{\text {inp }}-\theta_{\text {ninp }}(\mathrm{CT})
$$

To test whether the links and their complementarity would matter more for patents that build on scientific prior art, we use the following regression:

$$
\begin{aligned}
& V_{i f k}=\alpha+\theta_{\text {ips }} \text { InventorPartnerScience }_{i f k}+\theta_{\text {nips }} \text { NoInventorPartnerScience }_{i f k} \\
& +\theta_{\text {inps }} \text { InventorNoPartnerScience }{ }_{i f k} \\
& +\theta_{\text {ninps }} \text { NoInventorNoPartnerScience } \text { ifk }_{k} \\
& +\theta_{\text {ipns }} \text { Inventor PartnerNoScience } \text { ifk }_{1}+\theta_{\text {nipns }} \text { NoInventorPartnerNoScience }_{i f k} \\
& +\theta_{\text {inpns }} \text { InventorNoPartnerNoScience } \text { ifk }_{\text {if }} \\
& +\theta_{\text {ninpns }} \text { NoInventorNoPartner NoScience } \text { ifk }+ \\
& +\beta_{i} P_{i f k}+\gamma_{F} F_{f(t)}+\tau_{k}+\mu_{t}+\epsilon_{i f k}
\end{aligned}
$$

We can test whether complementarity between Partner and Inventor Links will be stronger for science-based patents than for non-science based. This is our main test of interest:

$$
\left(\theta_{\text {ips }}-\theta_{\text {nips }}\right)-\left(\theta_{\text {inps }}-\theta_{\text {ninps }}\right)>\left(\theta_{\text {ipns }}-\theta_{\text {nipns }}\right)-\left(\theta_{\text {inpns }}-\theta_{\text {ninpns })}(\mathrm{CTsns})\right.
$$

\subsection{Control Variables}

To obtain consistent estimates, we include control variables at the firm, inventor team, and patent level.

Firm-level controls. Controls at the firm level include firm characteristics affecting the value of patents. Moreover, we include firm characteristics which may be driving selection into an IMEC

\footnotetext{
${ }^{15}$ In the estimation we will use the NoInventorNoPartner patents as the excluded category and test the following equivalent equation: $\theta_{i p}-\theta_{\text {nip }}>\theta_{i n p}$
} 
partnership. Firm Size is calculated as the number of US patents filed by the firm in the 5 years before the application year of the focal patent. Firm Scope is the number of distinct IPC codes of a company's patents in the last five years. Company Age is the number of years since the company's first patent. Firm Citations is calculated as the average number of forward citations received within 5 years by the patents of the firm filed in the last five years. Finally, we control for the location of firm headquarters (US, Europe, Japan, other), and whether the firm is in the top 25 of largest semiconductor firms in terms of sales.

Inventor-level controls. Inventor Count controls for the number of inventors listed on the patent, Inventor Experience for the average number of prior patents developed by the inventors, and Inventor Citations for the average number of forward citations of their prior patents within 5 years. We calculate inventor experience and citations using all prior US patents of the inventors on the focal patent (Li et al. 2014).

Patent-level controls. At the patent level, we include count patent classes and count claims as the number of patent classes and claims the patent lists. Count jurisdictions, the number of different jurisdictions in which the patent is protected, and count backward citations control for the scope of the patent (e.g., Corredoira and Banerjee 2015, Nemet and Johnson 2011). We also include indicators for filing year and technology field as defined by Fraunhofer (OECD 1994). ${ }^{16}$

\subsection{Selection issues}

Estimating the effects of mobile inventors and firm partnership on the value of patents runs into two major selection issues. First, any premium for firms which are IMEC partners could arise because more innovative firms become a partner, rather than that the activities associated with the partnership cause the firm to generate more valuable patents. Second, any premium for mobile inventors could arise due to mobile inventors creating more valuable patents already prior to mobility. While firm or inventor fixed effects would remove all time invariant unobserved characteristics, our sample is too small to run this type of analysis. Moreover, firms do not switch partnership status during the sample period. Instead, we test whether selection is affecting our results by analyzing observable firm and inventor characteristics which might drive selection. In the robustness section (Section 5.3.3) we look at whether mobile inventors develop more valuable patents prior to mobility and whether partner firms develop more valuable patents on average compared to non-partners.

\section{Results}

\subsection{Descriptive analysis}

${ }^{16}$ The main findings are robust to using indicators for US main patent classes and patent grant year. 
Table 1 shows descriptive statistics on the value of patents depending on the (combination of) linking mechanisms being used. The descriptive statistics support the value enhancing effect of combining inventor- and institutional-level links. ${ }^{17}$ Patents created by mobile inventor receive on average more citations compared to patents of non-mobile inventors (6.33 versus 4.08; mean comparison ttest: $\mathrm{p}=0.00$ ), confirming the existing literature which suggests the importance of these inventors for creating higher quality patents. We do not find significant differences between partner and nonpartner patents. Yet, the higher value of patents developed by mobile inventors is driven by patents assigned to partner firms. In line with our expectations on the importance of combining an institutional and an inventor link, we find that patents assigned to partners and mobile inventors have the largest number of forward citations. They receive more forward citations compared to patents of partner firms without an inventor link ( 6.96 versus 3.57; mean comparison ttest: $p=0.00$ ), and more forward citations compared to patents with an inventor link but no partner link (6.96 versus 3.87; mean comparison ttest: $\mathrm{p}=0.22$ ). The latter category unfortunately only has 45 patents, rendering the difference statistically insignificant. This low number of observations for mobile inventors at nonpartner firms may reflect, in line with our complementarity story, the difficulty for non-partners to recruit mobile inventors from IMEC. At the same time, an explicit test for complementarity (CT) will be more difficult with one of the 4 categories being sparsely populated.

Insert Table 1 here

To check whether the involvement of mobile researchers is more important for sciencerelated projects, Table 2 shows the average number of forward citations for the different categories split by science. The descriptive statistics confirm that particularly patents combining inventor and partner links, and which rely on scientific prior art receive the largest number of citations. The premium of this group over the other categories is substantial with an average of 13 forward citations. Although this groups has a higher variance in citations, with a maximum of 106 forward citations, the result is not driven by a few outliers, as one quarter of all patents in this group receive more than 14 citations. Patents that combine both inventor and partner links but do not rely on science receive significantly fewer citations (InventorPartnerScience versus InventorPartnerNoScience: 13.08 versus 2.42; mean comparison ttest: $\mathrm{p}=0.00$ ). Interestingly, non-partners do not seem to perform better on science-related projects with inventors poached from IMEC (InventorNoPartnerScience versus InventorNoPartnerNoScience: 3.67 versus 3.92, mean comparison ttest: $\mathrm{p}=0.20$ ). Unfortunately, the category of InventorNoPartnerScience has only 9 patents, which makes it difficult to find robust different patterns for this group. Again, the low number of cases where non-partners have their inventors from IMEC work on science-related projects rather than non-science related projects $(9$

17 Table A.1 in Appendix presents the descriptive statistics for all variables used in the analysis. 
versus 36) is suggestive of the need for a complementarity partnership link with IMEC to be able to better use mobile inventors, particularly for science related projects.

Insert Table 2 here

In summary, the descriptive results suggest that mobile inventors, who were actively involved in basic research projects at IMEC, allow their employing firms to generate more valuable inventions. Yet, the successful translation of more basic knowledge from IMEC into valuable firm inventions only holds when these mobile inventors work at firms with an institutional partnership link with IMEC and in case they work on science-based technologies. These descriptive statistics are already supportive for the positive impact from combining institutional and individual level links, at least for science-related projects. Maybe more surprising, given all the literature on inventor networks and mobility, is the finding that the sole use of the inventor link without an institutional link is not effective. The remarkable low number of patents developed by mobile inventors at non-partner firms presumably reflect the complementarity effect between the institutional and individual links with basic research. At the same time, the low number of such cases will make it more difficult to test for complementarity in the subgroup of science related projects, which is our target group of interest. ${ }^{18}$

\subsection{Multivariate analysis}

Tables 3 and 4 show the multivariate results from estimating (R.1) and (R.2). Model (1) in Table 3 confirms previous research that patents that build on scientific prior art receive more citations. They receive $45 \%$ more citations compared to patents which do not rely on science as prior art. The most significant control variables are the technology breadth of the patent (Count patent classes), the number of claims, and the average quality of past patents created by the inventors (Inventor citations). Moreover, patents of semiconductor companies which are in the top 25 of industry sales receive fewer citations. These variables are important controls for the potential inventor and partner firm selection bias.

Model (2) confirms previous research that patents developed by mobile inventors are more valuable. These patents receive on average $47 \%$ more citations compared to patents developed by non-mobile inventors, all else equal. Model (3) shows that this premium for mobile inventors only holds on science-related projects. Patents developed by mobile inventors and relying on science

\footnotetext{
${ }^{18}$ Because of the low frequency of occurrence in the InventorNoPartner case (45 patents), especially in the InventorNoPartnerScience case ( 9 patents) we prefer to use exclusive categories in the complementarity analysis rather than using interaction effects. The triple interaction InventorPartnerScience, which would be our main variable of interest, would correlate very strongly with the double interactions, particularly InventorScience, having only 9 observations to make the difference. Using exclusive categories for InventorPartnerScience eliminates this multicollinearity problem and should leave more robust estimates for $\theta_{i p s}$. It does however not eliminate the problem of $\theta_{\text {inps }}$ to be imprecisely estimated, which will hamper the significance of the complementarity tests (CTs and CTsns).
} 
receive $136 \%$ more citations compared to patents relying on science but not developed by mobile inventors, and $152 \%$ more citations compared to patents developed by mobile inventors but not relying on science. Hence, the premium for mobile inventors on science-related projects is substantial even compared to other science-related projects without mobile inventors. These results confirm the importance of mobile inventors that can bridge between science and technology particularly for generating high impact inventions that rely on science.

In contrast to the importance of mobile inventors, partner firms that develop IMEC-related technologies only marginally and non-significantly outperform non-partner firms (model (4)). This finding illustrates once more that a selection of more innovative firms into an IMEC partnership is unlikely. However, science-related patents of partners significantly outperform non-science-related partner patents, an effect we do not find for non-partners (model (5)). Patents developed by partners and relying on science receive $62 \%$ more citations compared to patents developed by partners but not relying on science, and $30 \%$ more citations compared to non-partner patents relying on science. These results suggest that the commitment provided by an institutional partnership helps to create more valuable inventions but only for those inventions that are science-based.

Insert Table 3 here

Model (6) corresponds to our main model (R.1) looking at the effect of combining both bridging mechanisms. The results support complementarity between individual and institutional bridging mechanisms, as $\theta_{i p}$ is the only coefficient that is significant. Patents which combine a mobile inventor and a partner link receive, all else equal, $58 \%$ more citations compare to patents of mobile inventors and non-partner firms, and 70\% more citations compared to patents developed without a mobile inventor, but within a partner firm. However the strict test for complementarity (CT) is only significant at the $15 \%$ level.

We examine the potential complementarity between partner and inventor links and the role of science related projects by looking at different splits of the sample. Model (7) in Table 3 shows the results for the subset of 417 patents which are science-linked (science). In this subsample we only find a strong and significant coefficient for patents combining an inventor and a partner link. The test for complementarity is significant at the $10 \%$ level. In the subsample of 672 non-science related patents (model (8) of Table 3) we find no significant coefficients and no significant complementarity test. Columns (9) and (10) in Table 3 show the analysis for the sample of partner respectively non-partner patents. It takes the selection into partnership as given and looks within each group which inventions are more valuable. Within the group of partner firms, the results confirm that an inventor link is most supportive for the development of more valuable inventions but only when it involves a sciencerelated project. For non-partner firms, no significant effect is found for an inventor link, not even on science-related projects. Columns (11) and (12) in Table 3 show the results splitting the sample by mobile inventors. In the sample of 221 patents with mobile inventors, we find the highest quality 
premium when these mobile inventors work for firms with a partner link. This seems to hold the more so when they work on science related projects where the difference is significant at the $5 \%$ level.

The regression for our full model (R.2) is reported in column (1) of Table 4. The only coefficient which is significant is $\theta_{i p s}$. Patents with an inventor and partner link, and which rely on scientific prior art, receive, all else equal, $211 \%$ more citations compared to patents with an inventor and partner link which do not rely on science, and receive 192\% more citations compared to patents which rely on science but have no partner and no inventor link. The citation premium for InventorPartnerScience patents is so substantial that the test for complementarity between an inventor and a partner link for science-related projects (CTs) is significant at the $10 \%$ level. For non-science related projects there is no evidence for impact from inventor nor partner links or from combining both links (CTns). The test that the complementarity from combining an inventor and an institutional link is stronger for science-related projects than for non-science related projects (CTsns), our main empirical prediction, is therefore significant at the $10 \%$ level. $^{19}$

\section{Insert Table 4 here}

Model (1) in Table 4 allows to further substantiate the effect that an inventor link only holds for patents that rely on scientific prior art (found in Table 3 model 4). It shows that the effect of an inventor link on science related patents only holds insofar the inventor moves to a firm which has an institutional partnership with IMEC, as InventorNoPartnerScience $\left(\theta_{\text {inps }}\right)$ is insignificant. Also, the coefficient of InventorPartnerNoScience $\left(\theta_{\text {ipns }}\right)$ is insignificant, confirming that mobile inventors develop more valuable patents at partners only for science-related projects. Hence, our expectation that mobile inventors are a pivotal mechanism for effective linking to basic research only seems to hold for firms that also have an institutional link and for science-related technologies.

Overall, the multivariate results in our full model and across different cuts of the data are in line with the descriptive results and consistent with our argument that the closer the invention is linked to scientific prior art, the more important it becomes to have a complementary set of bridging mechanisms, combining institutional and individual links.

\subsection{Robustness}

\subsubsection{Control Sample.}

Our results might be sensitive to the control sample of patents selected. As mentioned, we constructed our control sample using the set of patents that cite IMEC-owned patents in our source sample. We

${ }^{19}$ As a robustness check, we estimate model (R.2) using a negative binomial model. The results remain robust and even gain in significance. The test for higher complementarity for science-related projects compared to nonscience-related projects (CTsns) is significant at the 5\% level. Results are available from the authors upon request. 
argued that this helped us to construct a sample of patents in the relevant technology field for the IMEC-related and hence basic research related technologies. However, one might worry that this selection procedure excludes parallel but independent technology trajectories, or might introduce a particular bias related to the citing behavior of firms. We check the robustness of our findings by constructing for the inventor-linked patents a more standard control sample of patents sharing the same technology class (IPC4) and application year. ${ }^{20}$ Among the group of matching patents, we select for each Inventor Partner patent in our sample a control patent from the same firm with the closest application date and from the same technology class (IPC4). The only difference is that the patent is not developed by an inventor which has been working at IMEC. For the same set of Inventor Partner patents in our sample, we select an additional control patent sharing the same technology class (IPC4) and application year but assigned to a non-partner firm. Again we select the patent with the closest application date. Hence, we have for each of the 176 Inventor Partner patents a matched patent belonging to an IMEC partner and a matched patent belonging to a non-partner to control for both dimensions of interest, inventor link and partner link. For Inventor Non-Partner patents, we follow the same procedure to select a control patent that is assigned to a non-partner company but without an IMEC inventor. Note that because of the one-to-one pairing procedure, we have fewer observations in the alternative control group (379 observations). This affects particularly the science-related projects, as the alternative control group patents are less likely to rely on science, particularly for the nonpartner patents. ${ }^{21}$ The smaller number of observations will make it more difficult to find significant results.

When we compare these "matched control" patents to our original "citing" patents, we see that the InventorNoPartnerMatched patents have an average number of forward cites of 2.82. This compares to the 3.57 average forward cites of the InventorNoPartner patents used in the main analysis. For the NoInventorNoPartnerMatched patents we find an average number of forward cites of 2.72, compared to the 4.59 average forward cites of the NoInventorNoPartner patents used in the main analysis. As expected, we seem to bias against our results when using the citing control group, as matched control patents have fewer forward citations. Our initial control group based on citing patents is a more conservative control with a larger number of observations. Model (2) in Table 4 shows the regression results for this alternative control sample. Our main results continue to hold: patents developed by mobile inventors who moved between the research organization and the firm are more valuable but only as far as it involves science-related inventions which are developed within

\footnotetext{
${ }^{20}$ As technologies that attempt to bridge basic and applied research are unlikely randomly distributed within IPC classes, experimenting with alternative methods for constructing control samples might be quite fruitful in this environment. See for example Arts, Cassiman, and Gomez (2017) for the use of text-mining to construct casecontrol samples.

${ }^{21}$ There are only 37 patents (out of 176) assigned to non-mobile inventors working at a non-partner firm who cite science in the alternative control group sample.
} 
partner firms. The test for a higher complementarity between inventor and partner links on sciencerelated projects compared to non-science-related projects is however only significant at the $15 \%$ level.

\subsubsection{Mobile Inventors}

The fact that we exclusively trace mobile inventors between IMEC and companies implies that companies might hire researchers which have previously been involved in basic research in other research organizations or universities. Assuming that researchers actively accessing basic research develop more valuable patents, such inventor mobility outside of IMEC would bias the results against our findings. The fact that partner patents with an inventor link receive more citations suggests that the IMEC industrial affiliates program is probably more helpful compared to other means of linking to basic research. To more formally check this, we trace the patent histories of all inventors on NoInventorPartner and NoInventorNoPartner patents, and exclude patents from the analysis where at least one of the patent's inventors was found on a previous patent assigned to a university or a public research organization. ${ }^{22}$ Doing so, we drop 46 out of 435 NoInventorPartner patents (11\%) and 103 out of 433 NoInventorNoPartner patents (24\%), suggesting non-partner companies make relatively more use of mobile inventors outside IMEC compared to partner companies. The findings on the reduced sample displayed in column (3) in Table 4 confirm the highly significant coefficient for InventorPartnerScience and support a higher complementarity from linking both mechanisms for science-related projects $\left(\mathrm{CT}_{\text {sns }}\right.$ significant at $\left.<10 \%\right)$.

Finally, the results on mobile inventors within partner firms could be mainly driven by cases of roundtrip mobility whereby partner firms send their researchers to work as industrial residents at IMEC's lab and later on these researchers move back to the partner firm. If so, the existence of complementarity between the inventor and institutional link would be almost by construction. To study this issue, we identify cases of round trip mobility using information from IMEC's personnel database, web searches including LinkedIn profiles, and individual patenting histories. As a robustness check, we exclude partner patents developed by mobile inventors for whom there is any evidence that they worked at the partner firm before coming to IMEC. The findings in column (4) of Table 4 illustrate that our findings are robust if we exclude patents created by these roundtrip mobile inventors. This suggests that the effect for partners from employing IMEC inventors extends beyond their exclusive right to send their employees on a round-trip, but also results from being able to hire new recruits from the pool of IMEC inventors.

\subsubsection{Selection Issues.}

${ }^{22}$ The institutions which were most frequently occurring apart from IMEC are MIT, Cornell, California Institute of Technology and Princeton. 
To find out which firms are more likely to become a partner, we run a selection equation on the set of 87 firms in the sample, of which 33 are IMEC partners. This small number of firms restricts the robustness of any selection analysis. Nevertheless, we include the company's core technological area and all other firm characteristics mentioned supra. ${ }^{23}$ Results are reported in Appendix 2. The results show that US and especially EU firms, are more likely to become partners, as are leading semiconductor firms (among the top 25 in terms of sales) and firms with a larger patent stock. Most importantly, firms with higher average quality patents are not significantly more likely to become IMEC partners, rather less likely, although the coefficient is not significant. These results reassure that any positive findings for partners are unlikely to be due to an upward bias from firms with higher patent quality selecting into IMEC partnerships. To this end, it is important that we include the same firm characteristics relevant for selecting into a partnership in our main analysis. We decided not to integrate the firm selection equation into our estimation as we lack any clear exclusion restriction and are dealing with a reduced set of firms. ${ }^{24}$ With few and skewed observations to correct for firm selection, part of our analysis also involves taking the partner selection as given and examining for IMEC partners any differences between those that use a mobile inventor link and those that don't, while including proper inventor and firm controls.

There are various selection issues that arise with respect to mobile inventors. This group is composed of former IMEC employees, former visiting researchers sent by universities or public research organizations, and researchers sent by partner firms to IMEC. Only IMEC partners can send their researchers to work at IMEC's facilities. A first potential selection issue is that only the best inventors move from IMEC to the focal firm. A second potential selection issue is that partner firms might attract better mobile inventors from IMEC compared to non-partner firms. A third potential selection issue is that partner firms may send their best researchers, or because of appropriation concerns, precisely not the best.

Appendix 3 examines each potential selection issue by comparing each respective group of mobile inventors to a proper control group of inventors based on observable inventor characteristics that might affect selection. The results, though plagued by a small number of observations, ${ }^{25}$ show that among those inventors working at IMEC, the most prolific inventors in terms of the number of patents seem to move from IMEC to companies. Yet, and more important for our analysis, we do not

\footnotetext{
${ }^{23}$ To determine a company's core technological area, we classify a company's past patents using the 30 Fraunhofer technology classes based on IPC codes and take the most frequently occurring class as core technological area. In the estimation of the partner selection model, the technology classes which are not core to at least one partner firm are dropped and jointly treated as control group.

${ }^{24}$ As there are no standard routines to estimate selection models into PQML, we transformed our dependent variable into $\log (1+$ count $)$ and then tried to apply the etregress procedure in Stata. However, this failed to converge.

${ }^{25}$ We only have 57 mobile inventors of which 48 are at IMEC partners and 9 at non-IMEC partners.
} 
find significant differences in the average value of patents between those inventors who leave and those who stay at IMEC. Furthermore, the results suggest that mobile inventors who produce more but on average less valuable patents go to partners rather than non-partners. However, the differences are not statistically significant, potentially due to the small number of observations. Finally, partner firms do not select specific profiles of inventors to work at IMEC. Before their visit to IMEC, these inventors do not have more patents, more valuable patents, or patents with more citations to scientific literature compared to their co-inventors working in the same firm and on the same technologies.

\section{Discussion and Conclusion}

The analysis presented in the paper contributes to the literature on how firms access basic research and how this access can have an impact on the quality of their new inventions. Our contribution is to identify different bridging mechanisms - institutional partnerships and mobile inventors, to benefit from accessing basic research. We argue that for firms to most successfully access basic research knowledge and generate more valuable inventions, they need to combine institutional and individual level bridges, particularly for developing new inventions that build on scientific prior art.

We tested our predictions on firms in micro-electronics, accessing basic research through their links to IMEC, a basic research organization with the explicit mission to bridge the gap between basic research done at universities and applied research and development in the industry. The analysis finds that mobile inventors, i.e. company researchers who were previously engaged in basic research at IMEC's facilities, develop more valuable patents. An important new insight for the literature is that the inventor links are only supportive for the development of more valuable technologies when the inventions are science-related and only at those firms that have a formal partnership with IMEC. We argue that the commitment provided by the partnership signals the availability of resources and puts incentives in place for the integration of external basic research knowledge into the firm's innovation process. Incorporating mobile inventors in more tacit and complex science-based technology development projects has a higher payoff in such an environment.

Our paper is in line with the results found by Ziedonis and Ziedonis (2005) for the case of Sematech, a research consortium specialized in semiconductor manufacturing. They find that technologies developed by the consortium or one of its partners are more valuable, particularly for members who build on these patents more extensively compared to non-members. Being able to track the movement of inventors and identify partner effects separately allows us to further refine these results by showing the importance of combining a mobile inventor link with a link at the institutional level. While they also find positive effects from institutional membership to Sematech, our IMEC research setting allows uncovering the critical complementary mobile inventor link for bridging into basic research when it concerns developing higher valued technologies which are science based.

Our results, although suffering from a small number of observations, are nevertheless supportive of the paper's research strategy. If we want to better understand how firms can capture 
value from linking to basic research by developing higher quality applied technologies, we need to look at the portfolio of bridging mechanisms - individual inventor links and institutional links - rather than at the deployment of a single bridging mechanism, as is typically done in the literature. It also supports the importance of identifying the nature of the projects where complementarity effects from combining several bridging mechanisms play out most significantly.

At the same time, the results also suggest important avenues for further research. First and foremost, replications of our research strategy on more and larger cases is needed to establish robustness of the reported results within and beyond the case of semiconductors and for IMEC as institute for access to basic research. The proposed research methodology is sufficiently generic that it can be applied to other cases, conditional on patents being a relevant indicator for new technological developments. The methodology can be applied to other industries, such as pharmaceuticals, or other technologies which are in different stage of development (mature versus emerging). The methodology can also be applied to other bridging institutes, which may be positioned in other types of research compared to the basic research in which IMEC specializes. These include the range from university research centers positioned in pure, non-oriented basic research to more applied oriented research centers, such as the Fraunhofer institutes. Replication of the analysis to these other cases would allow analyzing the sensitivity of the results for the nature of the technologies considered. Second, further analysis should extend the set of mechanisms to bridge the gap with basic research (e.g. copublications). Moreover, while we study partnerships as the mechanism for firms to commit and allocate resources to bridging the gap and embed the basic research knowledge of mobile inventors, alternative institutional mechanisms might have developed in different industries. Third, more information on how firms organize internally for effectively integrating this knowledge from case studies at partnering and non-partnering firms would be helpful to fine tune the mechanisms of access and translation. At the same time this would inform the partner and inventor selection analysis. Currently, we are unable to eliminate all sources of unobserved heterogeneity that might be affecting our results. For example, partner firms might be able to match better with IMEC inventors. But given our analyses, these matches would not be related to obvious observable characteristics of these firms and inventors. Irrespective of the actual mechanism, the bridging mechanisms seem to interact in generating these favorable outcomes. Fourth, our patent based data do not allow us to determine eventual commercial success of these technologies. Our interviews did indicate important lags in generating actual commercial results. Furthermore, many of the developed technologies relate to process technologies used by the companies internally and which are difficult to value commercially. Fifth, alternative ways to establish proper control groups of patents should be explored which would better identify comparable patents than through a citation link or a same patent classification code. Sixth, in order to better understand what makes the IMEC model successful, a more in-depth study of IMEC is in order. As IMEC is not characterized by major regime shifts over time, which would allow pin-pointing critical characteristics for success, such as its residency program and its IP model, 
comparing with other research consortia designs is a more promising avenue to understand what makes IMEC special. Sematech and the Micro-electronics and Computer Technology Corporation for instance, are alternatively consortia models in semiconductors which differ sufficiently in terms of IP model, public and private funding, collaboration among partners, as well as in their success to make for a fruitful comparison analysis (Cassiman 1996, Ziedonis and Ziedonis 2005).

These results on complementarity between bridging mechanisms, when confirmed on further cases, would suggest that firms need to consider their portfolio of bridging mechanisms rather than individual mechanisms when designing their strategy to access basic research. For policy makers, the complementarity results suggest that some of the initiated programs such as the NSF Grant Opportunities for Academic Liaison with Industry program or the Industry-Academia Partnerships and Pathways of the Marie-Curie Program of the European Commission, which focus on individual bridging mechanisms to access basic research, will only be successful if embedded within tighter institutional mechanisms linking university and firm. These cross-institutional partnerships provide the commitment to resources and incentives within the firm's innovation process. Likewise, public programs supporting institutional collaboration between firms and public research organizations, should pay due attention to supporting individual mobility.

\section{References}

Adams, J. D. 1990. Fundamental Stocks of Knowledge and Productivity Growth, Journal of Political Economy, 98(4), 673-702

Agrawal, A. 2006. Engaging the inventor: Exploring licensing strategies for university inventions and the role of latent knowledge. Strategic Management Journal, 27(1), 63-79.

Aghion, P., \& Tirole, J. 1994. The management of innovation. The Quarterly Journal of Economics, 109(4), 1185-1209.

Aghion, P., M. Dewatripont, J. Kolev, F. Murray, S. Stern. 2009. Of Mice and Academics. Mimeo Harvard University, Cambridge, MA.

Ahuja, G., Lampert, C. M., and Tandon, V. (2008). Moving Beyond Schumpeter: Management Research on the Determinants of Technological Innovation. The Academy of Management Annals, 2(1), 1-98.

Alcacer J, Gittelman M 2006. Patent citations as a measure of knowledge flows: The influence of examiner citations. Rev. Econom. Statist. 88(4):774-779.

Alcacer J, Gittelman M, Sampat BN 2009. Applicant and examiner citations in U.S. patents: An overview and analysis. Res. Policy 38(2):415-427.

Allen, T. J. 1977. Managing the flow of technology. MIT Press, Boston, MA.

Almeida, P., B. Kogut. 1999. Localization of Knowledge and the Mobility of Engineers in Regional Networks, Management science, 45(7), 905-917.

Arora, A., Belenzon, S., \& Patacconi, A. 2018. The decline of science in corporate R\&D. Strategic Management Journal, 39(1), 3-32.

Arts, S.,B. Cassiman, J.C. Gomez 2017. Text Matching to Measure Patent Similarity. Strategic Management Journal 39(1): 62-84.

Audretsch, D.B., P.E. Stephan. 1996. Company-Scientist Locational Links: The Case of Biotechnology. Amer. Econom. Rev. 86(3) 641-652.

Bechky, B.A. 2003. Sharing Meaning Across Occupational Communities: The Transformation of Understanding on a Production Floor, Organization Science 14(3), 312-330.

Belderbos, R., M. Carree, B. Lokshin. 2004. Cooperative R\&D and Firm Performance. Res. Policy. 33(10) 1477-1492. 
Belderbos, R., M. Carree, B. Lokshin. 2006. Complementarity in R\&D Cooperation Strategies. Review of Industrial Organization. 28(4) 401-426.

Bessen, J. 2011. From Knowledge to Ideas: The Two Faces of Innovation. Working paper No. 10-35, Boston University School of Law.

Brandstetter, L., M. Sakakibara. 1998. Japanese research consortia: a microeconometric analysis of industrial policy. J. Indust. Econom. 46: 207-233.

Breschi, S., C. Catalini. 2010. Tracing the links between science and technology: An exploratory analysis of scientists' and inventors' networks. Res. Policy. 39(1) 14-26.

Callaert, J., J. Grouwels, B. Van Looy. 2012. Delineating the scientific footprint in technology: Identifying scientific publications within non-patent references. Scientometrics. 91(2) 383398.

Cañibano, C., J. Otamendi, I. Andujar. 2008. Measuring and Assessing Researcher Mobility From CV Analysis: the Case of the Ramon y Cajal Programme in Spain. Research Evaluation. 17(1): 17-31.

Cassiman, B. 1996. Cooperation in Research and Development. Ph.D. thesis, Northwestern University, Evanston, IL.

Cassiman, B., D. Perez-Castrillo, R. Veugelers. 2002. Endogenizing Know-how Knows through the Nature of R\&D Investments. International Journal of Industrial Organization. 20(6) 775-799.

Cassiman, B., R. Veugelers. 2006. In Search of Complementarity in the Innovation Strategy: Internal R\&D and External Knowledge Acquisition. Management Sci. 52(1) 68-82.

Cassiman, B., R. Veugelers, P. Zuniga. 2008. In search of Performance Effects of (in)direct Industry Science Links. Indust. Corporate Change. 17(4) 611-646.

Cockburn, I.M., R. Henderson. 1996. Public-private interaction in pharmaceutical research, PNAS, 93(23), 12725-12730.

Cockburn, I.M., R. Henderson. 1998. Absorptive Capacity, Coauthoring Behavior, and the Organization of Research in Drug Discovery. The J. Indust. Econom. 46(2) 157-182.

Cohen, W.M., D.A. Levinthal. 1989. Innovation and learning: the two faces of R\&D. The Economic Journal. 99(397) 569-596.

Cohen, W.M., R. Nelson, J. Walsh. 2002. Links and impacts: The influence of public research on industrial R\&D. Management Sci. 28(1) 1-23.

Corredoira, R. A., \& Banerjee, P. M. 2015. Measuring patent's influence on technological evolution: A study of knowledge spanning and subsequent inventive activity. Research Policy, 44(2), 508-521.

Dasgupta, P., P. A. David. 1994. Toward a new economics of science. Research policy 23(5) 487-521.

d'Aspremont, C., A. Jacquemin, 1988. Cooperative and Noncooperative R \& D in Duopoly with Spillovers, The American Economic Review, 78(5), 1133-1137

Ejsing, A. K., Kaiser, U., Kongsted, H. C., \& Laursen, K. (2013). The Role of University Scientist Mobility for Industrial Innovation (No. 7470). IZA Discussion Paper.

Evenson, R.E., Y. Kislev. 1976. A Stochastic Model of Applied Research. J. Political Econom. 84(2) 265-282.

Fabrizio, K. 2009. Absorptive Capacity and the Search for Innovation. Res. Policy. 38(2) 255-267.

Fleming, L., O. Sorenson. 2004. Science as a map in technological search. Strategic Management J. 25 909-928.

Foray, D., F. Lissoni. 2010. University Research and Public-Private Interaction, in: B.H. Hall, N. Rosenberg (ed.), Handbook of the Economics of Innovation, 1, 275-314, Elsevier NorthHolland.

Gambardella, A. 1995. Science and innovation: the US pharmaceutical industry during the 1980s. Cambridge University Press, Cambridge, U.K.

Gambardella, A., D. Harhof, B. Verspagen. 2008. The value of European patents. European Management Review. 5 69-84.

Gittelman, M., B. Kogut. 2003. Does Good Science Lead to Valuable Knowledge? Biotechnology Firms and the Evolutionary Logic of Citation Patterns. Management Sci. (49)4 366-382.

Gourieroux, C., A. Monfort, A. Trognon. 1984. Pseudo Maximum Likelihood Methods: Applications to Poisson Models. Econometrica. 52(3) 701-720.

Griliches, Z. 1998. R\&D and Productivity: The Econometric Evidence, University of Chicago Press, Chicago, US 
Hansen, M.T. 1999. The Search-Transfer Problem: The Role of Weak Ties in Sharing Knowledgeacross Organization Subunits, Administrative Science Quarterly, 44, 82-111.

Harhoff, D., F. Narin, F. Scherer, K. Vopel. 1999. Citation Frequency and the Value of Patented Inventions. The Review of Economics and Statistics. 81(3) 511-515.

Henderson, R., I.M. Cockburn. 1996. Scale, Scope, and Spillovers: The Determinants of Research Productivity in Drug Discovery. RAND J. Econom. 27(1) 32-59.

Hoisl, K. 2007. Tracing Mobile Inventors: The Causality between Inventor Mobility and Inventor Productivity. Research Policy, 36 (5): 619-636.

Hoisl, K. 2009. Does Mobility Increase the Productivity of Inventors? Journal of Technology transfer, 34(2): 212-225.

Jaffe, A.B. 1989. Real Effects of Academic Research, The American Economic Review, 79(5), 957970.

Jensen, R., M. Thursby. 2001. Proofs and Prototypes for Sale: The Licensing of University Inventions, The American Economic Review, 91(1), 240-259.

Kamien, M. I., Muller, E., \& Zang, I. (1992). Research joint ventures and R\&D cartels. The American Economic Review, 1293-1306.

Kotha, R., G. George, and K. Srikanth, 2013 Bridging the Mutual Knowledge Gap: Coordination and the Commercialization of University Science, Academy of Management Journal, 56(2), 498524.

Lemley MA, Sampat B 2012. Examiner characteristics and patent office outcomes. Rev. Econom. Statist. 94(3):817-827.

Li GC, Lai R, D’Amour A, Doolin DM, Sun Y, Torvik VI, Yu AZ, Fleming L. 2014. Disambiguation and co-authorship networks of the US patent inventor database 1975-2010, Research Policy 43(6): 941-955.

Lacetera, N. 2009. Different Missions and Commitment Power in R\&D Organization: Theory and Evidence on Industry-University Relations. Organ. Sci. 20 (3) 565-582.

Laursen, K., \& Salter, A. 2006. Open for innovation: the role of openness in explaining innovation performance among UK manufacturing firms. Strategic management journal, 27(2), 131-150.

Leonard-Barton, D. 1984. Interpersonal communication patterns among Swedish and Boston-area entrepreneurs, Research Policy, 13(2), 101-114.

McEvily, B., G. Soda, M. Tortoriello. 2014. More formally: Rediscovering the missing linkbetween formal organization and informal social structure, The Academy of Management Annals, 8(1), 299-345.

Mansfield, E. 1995. Academic Research Underlying Industrial Innovations: Sources, Characteristics, and Financing. The Review of Economics and Statistics. 77(1) 55-65.

Mansfield, E. 1998. Academic research and industrial innovation: An update of empirical findings. Res. Policy. 26(7-8) 773-776.

Meyer-Krahmer, F., U. Smoch. 1998. Science-based technologies: university-industry interactions in four fields. Res. Policy. 27(8) 835-851.

Nelson, R. 1959. The Simple Economics of Basic Scientific Research. J. Political Econom. 67(3) 297-306.

Nemet, G. F., \& Johnson, E. 2012. Do important inventions benefit from knowledge originating in other technological domains?. Research Policy, 41(1), 190-200.

OECD. 1994. The Measurement of Scientific and Technological Activities: Using Patent Data as Science and Technology Indicators, Patent Manual. OECD/GD(94)114, Paris.

OECD. 2002. Frascati manual: Proposed Standard Practice for Surveys on Research and Experimental Development.

Roach, M., \& Cohen, W. M. 2013. Lens or prism? Patent citations as a measure of knowledge flows from public research. Management Science, 59(2), 504-525.

Rogers, E. M., \& Larsen, J. K. (1984). Silicon Valley fever: Growth of high-technology culture (p.189). New York: Basic books.

Rosenberg, N., R.R. Nelson. 1994. American universities and technical advance in industry, Research policy, 23(3), 323-348.

Silva, J. S., \& Tenreyro, S. 2006. The log of gravity. The Review of Economics and Statistics. 88(4) 641- 658 . 
Singh, J., A. Agrawal. 2011. Recruiting for Ideas: How Firms Exploit the Prior Inventions of New Hires. Management Sci. 57(1) 129-150.

Song, J., Almeida, P., \& Wu, G. (2003). Learning-by-Hiring: When is mobility more likely to facilitate interfirm knowledge transfer? Management Science,49(4), 351-365.

Trajtenberg, M. 1990. A Penny for Your Quotes: Patent Citations and the Value of Innovations. RAND J. Econom. 21(1) 172-187.

Tsai, W. 2001. Knowledge transfer in intraorganizational networks: Effects of network position and absorptive capacity on business unit innovation and performance. Academy of management journal, 44(5), 996-1004.

Tzabbar, D., Aharonson, B. S., Amburgey, T. L., \& Al-Laham, A. (2008). When is the whole bigger than the sum of its parts? Bundling knowledge stocks for innovative success. Strategic Organization, 6(4), 375-406.

Tzabbar, D., Aharonson, B. S., \& Amburgey, T. L. 2013. When does tapping external sources of knowledge result in knowledge integration?. Research Policy, 42(2), 481-494.

Tushman, M., T. Scanlan. 1981.Boundary Spanning Individuals: Their Role in Information Transfer and Their Antecedents. Acad. Management J. 24( 2) 289-305.

Van Helleputte, J.C., A. Reid. 2004. Tackling the paradox: can attaining global research excellence be compatible with local technology development? R\&D Management. 34(1) 33-44.

Veugelers, R., B. Cassiman. 2005. R\&D Cooperation Between Firms and Universities: Some empirical evidence from Belgian manufacturing. International journal of Industrial Organization. 23(5-6) 355-379.

Ziedonis, A., R.H. Ziedonis. 2005. Research Consortia as Performers and Brokers of R\&D: Tradeoffs for Member Firms. Mimeo, Ross School of Management, Ann Arbor, MI.

Zucker, L.G., M.R. Darby, M.B. Brewer. 1998. Intellectual Capital and the Birth of U.S. Biotechnology Enterprises. Amer. Econom. Rev. 88(1) 290-306.

Zucker, L.G., M.R. Darby, J.S. Armstrong. 2002. Commercializing Knowledge: University Science, Knowledge Capture, and Firm Performance in Biotechnology. Management Sci. 48(1) 138153. 
TABLE 1: Average Number of Forward Citations by Patent Type

\begin{tabular}{|c|c|c|c|c|c|c|c|c|}
\hline \multirow{2}{*}{$\begin{array}{c}\text { All } \\
(n=1089)\end{array}$} & \multirow{2}{*}{$\begin{array}{l}\text { Inventor } \\
(\mathrm{n}=221)\end{array}$} & \multirow{2}{*}{$\begin{array}{l}\text { No-inventor } \\
\qquad(\mathrm{n}=868)\end{array}$} & \multirow{2}{*}{$\begin{array}{l}\text { Partner } \\
(\mathrm{n}=611)\end{array}$} & \multirow{2}{*}{$\begin{array}{c}\text { No-partner } \\
(\mathrm{n}=478)\end{array}$} & \multicolumn{2}{|c|}{ Inventor } & \multicolumn{2}{|c|}{ No-Inventor } \\
\hline & & & & & $\begin{array}{c}\text { Partner } \\
(\mathrm{n}=176 \text { patents })\end{array}$ & $\begin{array}{c}\text { No-partner } \\
(\mathrm{n}=45 \text { patents })\end{array}$ & $\begin{array}{c}\text { Partner } \\
(\mathrm{n}=435 \text { patents })\end{array}$ & $\begin{array}{c}\text { No-partner } \\
(\mathrm{n}=433 \text { patents })\end{array}$ \\
\hline 5.98 & 6.33 & 4.08 & 4.55 & 4.52 & 6.96 & 3.87 & 3.57 & 4.59 \\
\hline
\end{tabular}

TABLE 2: Forward Citations by Patent Type and Science

\begin{tabular}{|c|c|c|c|c|c|c|c|}
\hline & & & & $\mathrm{N}$ & Mean & Stdev. & Max \\
\hline Science & & & & 417 & 6.06 & 12.04 & 106.00 \\
\hline No-science & & & & 672 & 3.60 & 6.03 & 55.00 \\
\hline \multirow{4}{*}{ Inventor } & \multirow{2}{*}{ Partner } & Science & Inventor, partner, science & 75 & 13.08 & 22.93 & 106.00 \\
\hline & & No-science & Inventor, partner, no-science & 101 & 2.42 & 4.34 & 19.00 \\
\hline & \multirow{2}{*}{ No-partner } & Science & Inventor, no-partner, science & 9 & 3.67 & 8.53 & 26.00 \\
\hline & & No-science & Inventor, no-partner, no-science & 36 & 3.92 & 9.23 & 54.00 \\
\hline \multirow{4}{*}{ No-inventor } & \multirow{2}{*}{ Partner } & Science & No-inventor, partner, science & 157 & 3.78 & 7.16 & 68.00 \\
\hline & & No-science & No-inventor, partner, no-science & 278 & 3.47 & 5.82 & 41.00 \\
\hline & \multirow{2}{*}{ No-partner } & Science & No-inventor, no-partner, science & 176 & 5.22 & 6.79 & 40.00 \\
\hline & & No-science & No-inventor, no-partner, no-science & 257 & 4.15 & 6.22 & 55.00 \\
\hline
\end{tabular}

Table 3: Forward Citations

\begin{tabular}{|c|c|c|c|c|c|c|c|c|c|c|c|c|}
\hline Sample & (1) & (2) & (3) & (4) & (5) & (6) & $\begin{array}{c}(7) \\
\text { Science } \\
\end{array}$ & $\begin{array}{c}(8) \\
\text { No-science } \\
\end{array}$ & $\begin{array}{c}(9) \\
\text { Partner } \\
\end{array}$ & $\begin{array}{c}(10) \\
\text { No-partner }\end{array}$ & $\begin{array}{c}(11) \\
\text { Inventor }\end{array}$ & $\begin{array}{c}(12) \\
\text { No- inventor }\end{array}$ \\
\hline Inventor & & $\begin{array}{c}0.382 * * \\
(0.175)\end{array}$ & & & $\begin{array}{l}0.334 * \\
(0.181)\end{array}$ & & & & & & & \\
\hline Partner & & & $\begin{array}{c}0.000 \\
(0.125)\end{array}$ & $\begin{array}{c}0.087 \\
(0.132)\end{array}$ & & & & & & & & \\
\hline Science & $\begin{array}{c}0.370 * * * \\
(0.113)\end{array}$ & $\begin{array}{c}0.367 * * * \\
(0.111)\end{array}$ & & $\begin{array}{c}0.372 * * * \\
(0.114)\end{array}$ & & $\begin{array}{c}0.358 * * * \\
(0.107)\end{array}$ & & & & & & \\
\hline Inventor, science & & & $\begin{array}{c}0.949 * * * \\
(0.215)\end{array}$ & & & & & & $\begin{array}{c}1.045^{* * *} \\
(0.313)\end{array}$ & $\begin{array}{l}-0.085 \\
(0.678)\end{array}$ & & \\
\hline Inventor, no-science & & & $\begin{array}{c}0.057 \\
(0.235)\end{array}$ & & & & & & $\begin{array}{c}0.224 \\
(0.377)\end{array}$ & $\begin{array}{c}0.243 \\
(0.316)\end{array}$ & & \\
\hline No-inventor, science & & & $\begin{array}{l}0.200^{*} \\
(0.118)\end{array}$ & & & & & & $\begin{array}{c}0.343^{* *} \\
(0.140)\end{array}$ & $\begin{array}{c}0.112 \\
(0.142)\end{array}$ & & \\
\hline Partner, science & & & & & $\begin{array}{c}0.416 * * \\
(0.169)\end{array}$ & & & & & & $\begin{array}{c}1.354 * * * \\
(0.312)\end{array}$ & $\begin{array}{c}0.138 \\
(0.180)\end{array}$ \\
\hline Partner, no-science & & & & & $\begin{array}{l}-0.103 \\
(0.124)\end{array}$ & & & & & & $\begin{array}{c}0.892 * * \\
(0.383)\end{array}$ & $\begin{array}{l}-0.037 \\
(0.127)\end{array}$ \\
\hline No-partner, science & & & & & $\begin{array}{c}0.197 \\
(0.147)\end{array}$ & & & & & & $\begin{array}{c}0.594 \\
(0.644)\end{array}$ & $\begin{array}{c}0.195 \\
(0.147)\end{array}$ \\
\hline Inventor, partner & & & & & & $\begin{array}{c}0.512 * * * \\
(0.187)\end{array}$ & $\begin{array}{c}0.667 * * * \\
(0.246)\end{array}$ & $\begin{array}{c}0.129 \\
(0.251)\end{array}$ & & & & \\
\hline Inventor, no-partner & & & & & & $\begin{array}{c}0.083 \\
(0.383)\end{array}$ & $\begin{array}{l}-0.512 \\
(0.809)\end{array}$ & $\begin{array}{c}0.116 \\
(0.324)\end{array}$ & & & & \\
\hline No-inventor, partner & & & & & & $\begin{array}{l}-0.029 \\
(0.144)\end{array}$ & $\begin{array}{l}-0.061 \\
(0.242)\end{array}$ & $\begin{array}{c}0.005 \\
(0.111)\end{array}$ & & & & \\
\hline Count patent classes & $\begin{array}{c}0.100 * * * \\
(0.019)\end{array}$ & $\begin{array}{c}0.096^{* * * *} \\
(0.019)\end{array}$ & $\begin{array}{c}0.089 * * * \\
(0.018)\end{array}$ & $\begin{array}{c}0.100 * * * \\
(0.019)\end{array}$ & $\begin{array}{c}0.095^{* * * *} \\
(0.019)\end{array}$ & $\begin{array}{c}0.096^{* * * *} \\
(0.018)\end{array}$ & $\begin{array}{c}0.133 * * * \\
(0.018)\end{array}$ & $\begin{array}{l}0.052^{*} \\
(0.032)\end{array}$ & $\begin{array}{c}0.105^{* * *} * \\
(0.015)\end{array}$ & $\begin{array}{c}0.017 \\
(0.033)\end{array}$ & $\begin{array}{c}0.115 * * * \\
(0.015)\end{array}$ & $\begin{array}{c}0.048 * * \\
(0.024)\end{array}$ \\
\hline Count claims & $\begin{array}{c}0.011 * * * \\
(0.003)\end{array}$ & $\begin{array}{c}0.011^{* * *} * \\
(0.003)\end{array}$ & $\begin{array}{c}0.011 * * * \\
(0.003)\end{array}$ & $\begin{array}{c}0.011 * * * \\
(0.003)\end{array}$ & $\begin{array}{c}0.011 * * * \\
(0.003)\end{array}$ & $\begin{array}{c}0.011^{* * * *} \\
(0.003)\end{array}$ & $\begin{array}{c}0.013 * * * \\
(0.004)\end{array}$ & $\begin{array}{c}0.004 \\
(0.003)\end{array}$ & $\begin{array}{c}0.010^{* *} \\
(0.005)\end{array}$ & $\begin{array}{c}0.005 \\
(0.004)\end{array}$ & $\begin{array}{c}0.000 \\
(0.010)\end{array}$ & $\begin{array}{c}0.008 * * * \\
(0.003)\end{array}$ \\
\hline Count jurisdictions & $\begin{array}{c}0.007 \\
(0.030)\end{array}$ & $\begin{array}{c}0.017 \\
(0.029)\end{array}$ & $\begin{array}{c}0.023 \\
(0.030)\end{array}$ & $\begin{array}{c}0.008 \\
(0.030)\end{array}$ & $\begin{array}{c}0.020 \\
(0.030)\end{array}$ & $\begin{array}{c}0.020 \\
(0.030)\end{array}$ & $\begin{array}{c}0.012 \\
(0.029)\end{array}$ & $\begin{array}{c}0.053 \\
(0.053)\end{array}$ & $\begin{array}{c}0.083 * * \\
(0.035)\end{array}$ & $\begin{array}{c}0.005 \\
(0.039)\end{array}$ & $\begin{array}{c}0.045 \\
(0.046)\end{array}$ & $\begin{array}{c}0.063 \\
(0.039)\end{array}$ \\
\hline Count backward citations & $\begin{array}{l}-0.004 * \\
(0.002)\end{array}$ & $\begin{array}{l}-0.003 \\
(0.002)\end{array}$ & $\begin{array}{l}-0.002 \\
(0.002)\end{array}$ & $\begin{array}{l}-0.004^{*} \\
(0.002)\end{array}$ & $\begin{array}{l}-0.003 \\
(0.002)\end{array}$ & $\begin{array}{l}-0.003 \\
(0.002)\end{array}$ & $(0.002)$ & $\begin{array}{c}0.003 \\
(0.003)\end{array}$ & $\begin{array}{l}-0.004 * \\
(0.002)\end{array}$ & $\begin{array}{c}0.004 \\
(0.003)\end{array}$ & $\begin{array}{l}-0.003 \\
(0.006)\end{array}$ & $\begin{array}{l}-0.002 \\
(0.002)\end{array}$ \\
\hline Inventor count & $\begin{array}{c}0.003 \\
(0.019)\end{array}$ & $\begin{array}{l}-0.003 \\
(0.018)\end{array}$ & $\begin{array}{l}-0.002 \\
(0.018)\end{array}$ & $\begin{array}{c}0.004 \\
(0.019)\end{array}$ & $\begin{array}{c}-0.002 \\
(0.018)\end{array}$ & $\begin{array}{c}-0.007 \\
(0.019)\end{array}$ & $\begin{array}{l}-0.003 \\
(0.030)\end{array}$ & $\begin{array}{c}-0.035 \\
(0.023)\end{array}$ & $\begin{array}{c}0.038 \\
(0.029)\end{array}$ & $\begin{array}{l}-0.026 \\
(0.028)\end{array}$ & $\begin{array}{c}0.014 \\
(0.040)\end{array}$ & $\begin{array}{l}-0.021 \\
(0.021)\end{array}$ \\
\hline Inventor experience & $\begin{array}{c}0.087 \\
(0.294)\end{array}$ & $\begin{array}{c}0.103 \\
(0.304)\end{array}$ & $\begin{array}{c}0.050 \\
(0.301)\end{array}$ & $\begin{array}{c}0.052 \\
(0.281)\end{array}$ & $\begin{array}{c}0.069 \\
(0.291)\end{array}$ & $\begin{array}{c}0.126 \\
(0.299)\end{array}$ & $\begin{array}{c}0.264 \\
(0.307)\end{array}$ & $\begin{array}{l}-0.950 \\
(0.791)\end{array}$ & $\begin{array}{l}-0.171 \\
(0.393)\end{array}$ & $\begin{array}{l}-0.052 \\
(0.412)\end{array}$ & $\begin{array}{c}8.372 * * * \\
(1.455)\end{array}$ & $\begin{array}{c}0.037 \\
(0.273)\end{array}$ \\
\hline Inventor citations & $\begin{array}{c}0.030 * * * \\
(0.006)\end{array}$ & $\begin{array}{c}0.030 * * * \\
(0.006)\end{array}$ & $\begin{array}{c}0.029 * * * \\
(0.006)\end{array}$ & $\begin{array}{c}0.029 * * * \\
(0.006)\end{array}$ & $\begin{array}{c}0.030 * * * \\
(0.006)\end{array}$ & $\begin{array}{c}0.029 * * * \\
(0.006)\end{array}$ & $\begin{array}{l}0.023 * \\
(0.012)\end{array}$ & $\begin{array}{c}0.021 * * * \\
(0.007)\end{array}$ & $\begin{array}{c}0.022 * * * \\
(0.008)\end{array}$ & $\begin{array}{c}0.036 * * * \\
(0.007)\end{array}$ & $\begin{array}{c}0.005 \\
(0.017)\end{array}$ & $\begin{array}{c}0.031 * * * \\
(0.005)\end{array}$ \\
\hline Headquarters US & $\begin{array}{l}-0.274 \\
(0.207)\end{array}$ & $\begin{array}{l}-0.074 \\
(0.167)\end{array}$ & $\begin{array}{c}0.077 \\
(0.168)\end{array}$ & $\begin{array}{l}-0.221 \\
(0.202)\end{array}$ & $\begin{array}{l}-0.021 \\
(0.164)\end{array}$ & $\begin{array}{c}0.041 \\
(0.161)\end{array}$ & $\begin{array}{c}0.213 \\
(0.234)\end{array}$ & $\begin{array}{c}0.387 * * \\
(0.192)\end{array}$ & $\begin{array}{c}0.165 \\
(0.288)\end{array}$ & $\begin{array}{c}0.139 \\
(0.292)\end{array}$ & $\begin{array}{l}-0.046 \\
(0.423)\end{array}$ & $\begin{array}{c}0.413 * * \\
(0.176)\end{array}$ \\
\hline Headquarters Japan & $\begin{array}{l}-0.256 \\
(0.204)\end{array}$ & $\begin{array}{l}-0.008 \\
(0.199)\end{array}$ & $\begin{array}{c}0.064 \\
(0.212)\end{array}$ & $\begin{array}{l}-0.182 \\
(0.214)\end{array}$ & $\begin{array}{c}0.011 \\
(0.210)\end{array}$ & $\begin{array}{c}0.088 \\
(0.194)\end{array}$ & $\begin{array}{c}0.205 \\
(0.368)\end{array}$ & $\begin{array}{c}0.260 \\
(0.212)\end{array}$ & $\begin{array}{c}0.314 \\
(0.356)\end{array}$ & $\begin{array}{c}-0.001 \\
(0.359)\end{array}$ & $\begin{array}{c}3.745^{* * * *} \\
(0.444)\end{array}$ & $\begin{array}{c}0.191 \\
(0.201)\end{array}$ \\
\hline Headquarters other & $\begin{array}{c}0.012 \\
(0.294)\end{array}$ & $\begin{array}{c}0.297 \\
(0.285)\end{array}$ & $\begin{array}{c}0.321 \\
(0.281)\end{array}$ & $\begin{array}{c}0.068 \\
(0.294)\end{array}$ & $\begin{array}{c}0.289 \\
(0.284)\end{array}$ & $\begin{array}{c}0.402 \\
(0.280)\end{array}$ & $\begin{array}{l}1.424 * * \\
(0.615)\end{array}$ & $\begin{array}{l}0.533^{*} \\
(0.314)\end{array}$ & $\begin{array}{c}0.582 \\
(0.458)\end{array}$ & $\begin{array}{c}0.243 \\
(0.504)\end{array}$ & & $\begin{array}{c}0.636^{* * *} * \\
(0.241)\end{array}$ \\
\hline Firm top 25 & $\begin{array}{c}-0.291 * * \\
(0.131)\end{array}$ & $\begin{array}{c}-0.271^{* *} \\
(0.125)\end{array}$ & $\begin{array}{c}-0.255^{*} \\
(0.132)\end{array}$ & $\begin{array}{c}-0.316^{* *} \\
(0.144)\end{array}$ & $\begin{array}{c}-0.277 * * \\
(0.138)\end{array}$ & $\begin{array}{c}-0.299^{* *} \\
(0.137)\end{array}$ & $\begin{array}{l}-0.295 \\
(0.201)\end{array}$ & $\begin{array}{c}-0.321 * * \\
(0.136)\end{array}$ & $\begin{array}{c}-0.348^{*} \\
(0.190)\end{array}$ & $\begin{array}{c}-0.313^{*} \\
(0.188)\end{array}$ & $\begin{array}{c}0.157 \\
(0.427)\end{array}$ & $\begin{array}{l}-0.257^{*} \\
(0.137)\end{array}$ \\
\hline Firm size & $\begin{array}{c}0.014 \\
(0.021)\end{array}$ & $\begin{array}{c}0.022 \\
(0.022)\end{array}$ & $\begin{array}{c}0.015 \\
(0.021)\end{array}$ & $\begin{array}{c}0.014 \\
(0.021)\end{array}$ & $\begin{array}{c}0.020 \\
(0.022)\end{array}$ & $\begin{array}{c}0.021 \\
(0.022)\end{array}$ & $\begin{array}{c}0.032 \\
(0.025)\end{array}$ & $\begin{array}{c}0.028 \\
(0.026)\end{array}$ & $\begin{array}{c}0.081 \\
(0.052)\end{array}$ & $\begin{array}{l}-0.013 \\
(0.021)\end{array}$ & $\begin{array}{l}-0.015 \\
(0.074)\end{array}$ & $\begin{array}{c}0.009 \\
(0.022)\end{array}$ \\
\hline Firm citations & $\begin{array}{c}0.010 \\
(0.015)\end{array}$ & $\begin{array}{c}0.009 \\
(0.014)\end{array}$ & $\begin{array}{c}0.006 \\
(0.014)\end{array}$ & $\begin{array}{c}0.009 \\
(0.015)\end{array}$ & $\begin{array}{c}0.007 \\
(0.014)\end{array}$ & $\begin{array}{c}0.010 \\
(0.014)\end{array}$ & $\begin{array}{c}0.021 \\
(0.024)\end{array}$ & $\begin{array}{c}0.002 \\
(0.014)\end{array}$ & $\begin{array}{l}0.064^{*} \\
(0.036)\end{array}$ & $\begin{array}{c}-0.014 \\
(0.015)\end{array}$ & $\begin{array}{c}0.197 * * * \\
(0.072)\end{array}$ & $\begin{array}{l}-0.008 \\
(0.013)\end{array}$ \\
\hline Firm scope & $\begin{array}{c}0.039 \\
(0.095)\end{array}$ & $\begin{array}{c}0.011 \\
(0.091)\end{array}$ & $\begin{array}{c}0.047 \\
(0.089)\end{array}$ & $\begin{array}{c}0.031 \\
(0.102)\end{array}$ & $\begin{array}{c}0.024 \\
(0.093)\end{array}$ & $\begin{array}{c}0.027 \\
(0.094)\end{array}$ & $\begin{array}{l}-0.101 \\
(0.172)\end{array}$ & $\begin{array}{c}0.017 \\
(0.073)\end{array}$ & $\begin{array}{c}-0.056 \\
(0.155)\end{array}$ & $\begin{array}{l}0.109^{*} \\
(0.066)\end{array}$ & $(0.182)$ & $\begin{array}{c}0.017 \\
(0.096)\end{array}$ \\
\hline Firm age & $\begin{array}{c}-0.006^{* *} \\
(0.003)\end{array}$ & $\begin{array}{l}-0.006^{*} \\
(0.003)\end{array}$ & $\begin{array}{l}-0.006^{*} \\
(0.003)\end{array}$ & $\begin{array}{c}-0.006^{* *} \\
(0.003)\end{array}$ & $\begin{array}{c}-0.006^{* *} \\
(0.003)\end{array}$ & $\begin{array}{l}-0.006^{*} \\
(0.003)\end{array}$ & $\begin{array}{c}-0.008 * * \\
(0.004)\end{array}$ & $\begin{array}{l}-0.001 \\
(0.003)\end{array}$ & $(0.003)$ & $\begin{array}{l}-0.001 \\
(0.004)\end{array}$ & $\begin{array}{c}0.003 \\
(0.005)\end{array}$ & $\begin{array}{l}-0.004 \\
(0.003)\end{array}$ \\
\hline $\begin{array}{l}\text { Log likelihood } \\
\text { Observations } \\
\text { Complementarity test (CT) }\end{array}$ & 1,089 & 1,089 & 1,089 & 1,089 & $\begin{array}{c}-3909.470 \\
1,089\end{array}$ & $\begin{array}{c}- \\
1,089 \\
p=0.151\end{array}$ & $\begin{aligned} & - \\
\mathrm{p}= & 0.083^{*}\end{aligned}$ & $\begin{array}{c}-2043.221 \\
672 \\
p=0.493\end{array}$ & 611 & $\begin{array}{c}-1488.860 \\
478\end{array}$ & $\begin{array}{c}-638.129 \\
221\end{array}$ & $\begin{array}{c}-2849.068 \\
868\end{array}$ \\
\hline
\end{tabular}

All models are estimated with Poisson Quasi Maximum Likelihood, and include technology and year dummies. Robust standard errors in brackets, clustered by firm, 
Table 4: Forward Citations All Categories

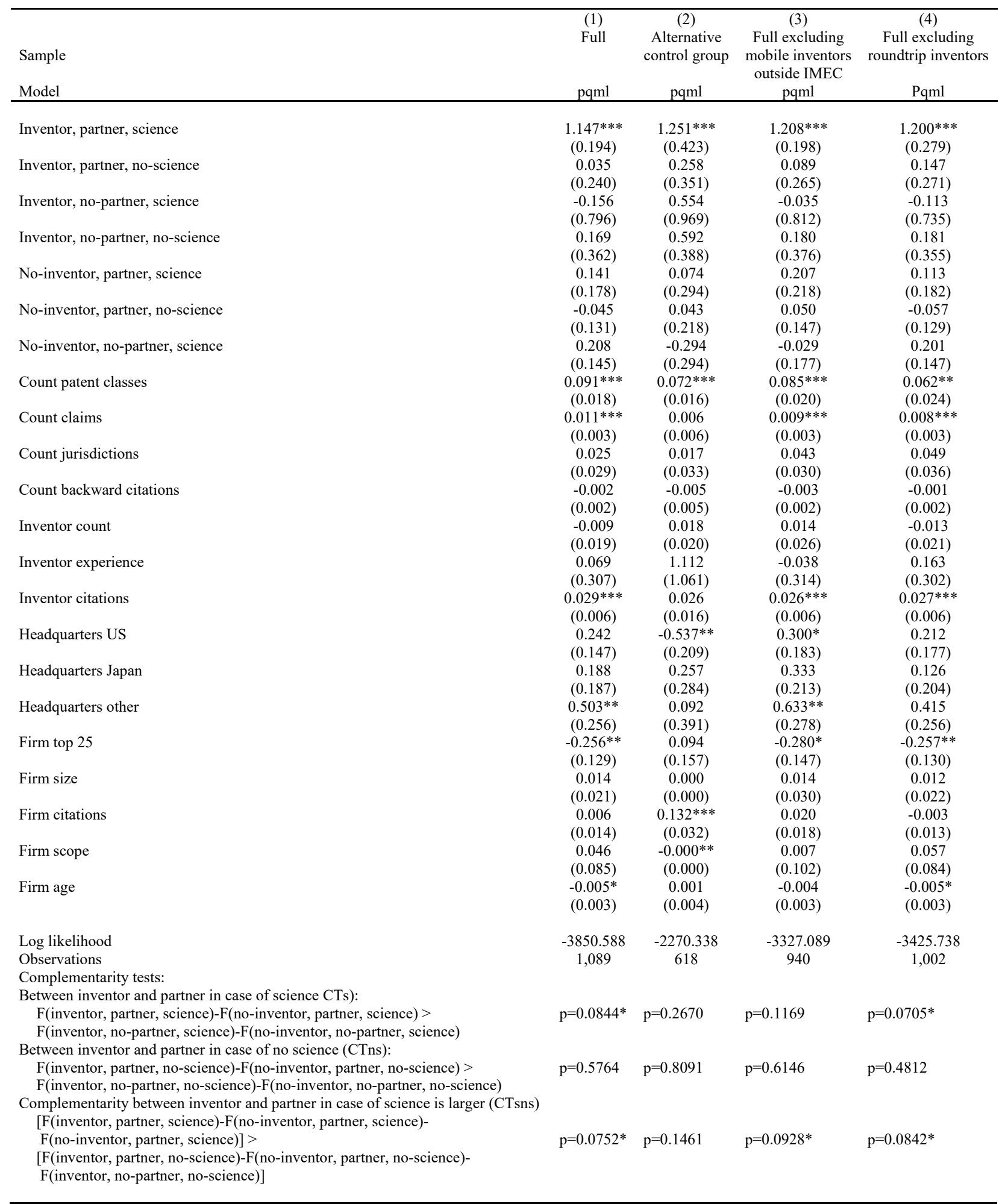

All models except model 4 are estimated with Poisson Quasi Maximum Likelihood, and include technology and year dummies. Model 4 is estimated with a negative binomial regression. Robust standard errors in brackets, clustered by firm. Alternative control patents are randomly drawn patents that share the same technology class (IPC4) and are filed around the same time as the focal patents. The control patents for patents assigned to partners and developed by mobile inventors are: patents assigned to a partner but having no inventor link (176), and patents assigned to a non-partner and having no inventor link (176). The control patents for patents assigned to non-partners and developed by mobile inventors are patents assigned to a non-partner company and having no inventor link (45). The number of observations of the latter group (221) equals the number of observations of patents from non-partners with inventors (45) plus the number of observations of patents from partners with inventor link $(176) . * * * p<0.01, * *$ $\mathrm{p}<0.05, * \mathrm{p}<0.1$ 
APPENDIX 1: Summary Statistics ( $n=1,089$ patents)

\begin{tabular}{|c|c|c|c|c|c|}
\hline Variables & Description & Mean & Stdev. & Min & Max \\
\hline Forward citations & $\begin{array}{l}\text { The number of times a patent is cited as prior art within five years after } \\
\text { application }\end{array}$ & 4.54 & 8.90 & 0.00 & 106.00 \\
\hline Inventor & Patent is developed by an inventor previously active in IMEC & 0.20 & & 0.00 & 1.00 \\
\hline Partner & Patent is developed by a company with an affiliation with IMEC & 0.56 & & 0.00 & 1.00 \\
\hline Science & Patent cites at least one publication from the Web of Science & 0.38 & & 0.00 & 1.00 \\
\hline Count patent classes & The number of IPC codes & 2.58 & 2.07 & 1.00 & 14.00 \\
\hline Count claims & The patent's number of claims & 17.72 & 13.22 & 1.00 & 147.00 \\
\hline Count jurisdictions & The number of different jurisdiction in which the patent is protected & 1.94 & 1.59 & 1.00 & 12.00 \\
\hline $\begin{array}{l}\text { Count backward } \\
\text { citations }\end{array}$ & The number of backward patent citations & 30.41 & 31.43 & 0.00 & 147.00 \\
\hline Inventor count & The number of inventors on the patent & 2.94 & 2.10 & 1.00 & 15.00 \\
\hline Inventor experience & $\begin{array}{l}\text { The number of patents applied for by at least one of the inventors before } \\
\text { the application (in ' } 000 \text { ) }\end{array}$ & 0.07 & 0.15 & 0.00 & 2.08 \\
\hline Inventor citations & $\begin{array}{l}\text { The average number of forward citations received within } 5 \text { years by } \\
\text { prior patents of at least one of the inventors }\end{array}$ & 5.98 & 4.39 & 0.00 & 60.00 \\
\hline Headquarters US & & 0.62 & & 0.00 & 1.00 \\
\hline Headquarters Japan & & 0.16 & & 0.00 & 1.00 \\
\hline Headquarters EU & & 0.17 & & 0.00 & 1.00 \\
\hline Headquarters other & & 0.05 & & 0.00 & 1.00 \\
\hline Firm top 25 & Firm belongs to 25 largest semiconductor firms in sales & 0.57 & & 0.00 & 1.00 \\
\hline Firm size & $\begin{array}{l}\text { The number of patents the applicant company applied for in the last } 5 \\
\text { years (in '000) }\end{array}$ & 4.25 & 4.39 & 0.00 & 19.99 \\
\hline Firm citations & $\begin{array}{l}\text { The average number of forward citations received within } 5 \text { years by the } \\
\text { patents assigned to the company applied for in the last } 5 \text { years }\end{array}$ & 5.98 & 4.39 & 0.00 & 28.59 \\
\hline Firm scope & $\begin{array}{l}\text { The number of unique IPC codes appearing on the company's patents } \\
\text { applied for in the last } 5 \text { years (in ' } 000 \text { ) }\end{array}$ & 1.27 & 1.16 & 0.00 & 5.13 \\
\hline Firm age & The number of years since the company's first patent & 50.92 & 28.19 & 4.00 & 109.00 \\
\hline
\end{tabular}

\section{APPENDIX 2: Partner Selection}

\section{Summary Statistics Partner vs Non-Partner}

\begin{tabular}{|l|c|c|}
\hline & $\begin{array}{c}\text { Partner } \\
\text { (33 firms) }\end{array}$ & $\begin{array}{c}\text { No-partner } \\
\text { (54 firms) }\end{array}$ \\
\hline Headquarters & & \\
\hline US & $45 \%$ & $67 \%$ \\
EU & $33 \%$ & $9 \%$ \\
Japan & $18 \%$ & $17 \%$ \\
Other & $4 \%$ & $7 \%$ \\
\hline Firm Characteristics & & \\
\hline Firm top 25 & $45 \%$ & $28 \%$ \\
Firm size & 1.87 & 0.96 \\
Firm citations & 7.29 & 8.54 \\
Firm scope & 0.96 & 0.60 \\
Firm age & 44.39 & 40.96 \\
\hline Firm Core Technology & & \\
\hline Semiconductors & $42 \%$ & $19 \%$ \\
Information technology & $15 \%$ & $15 \%$ \\
Optics & $12 \%$ & $7 \%$ \\
Electrical machinery and apparatus, electrical energy & $9 \%$ & $6 \%$ \\
Telecommunications & $6 \%$ & $30 \%$ \\
Analysis, measurement, control technology & $6 \%$ & $7 \%$ \\
Audio-visual technology & $3 \%$ & $2 \%$ \\
Others & $3 \%$ & $13 \%$ \\
\hline
\end{tabular}


Partner Selection Equation

\begin{tabular}{|c|c|}
\hline & Partner \\
\hline \multicolumn{2}{|l|}{ Firm Core Technology } \\
\hline Electrical machinery and apparatus, electrical energy & $\begin{array}{l}-0.201 \\
(0.854)\end{array}$ \\
\hline Audio-visual technology & $\begin{array}{l}-1.159 \\
(0.939)\end{array}$ \\
\hline Telecommunications & $\begin{array}{l}-0.753 \\
(0.705)\end{array}$ \\
\hline Information technology & $\begin{array}{l}-0.175 \\
(0.700)\end{array}$ \\
\hline Semiconductors & $\begin{array}{l}1.448^{* *} \\
(0.605)\end{array}$ \\
\hline Optics & $\begin{array}{c}0.523 \\
(0.650)\end{array}$ \\
\hline Analysis, measurement, control technology & $\begin{array}{c}0.666 \\
(0.807)\end{array}$ \\
\hline Chemical engineering & $\begin{array}{c}1.472 \\
(0.983)\end{array}$ \\
\hline \multicolumn{2}{|l|}{ Headquarters } \\
\hline US & $\begin{array}{c}-1.869 * * * \\
(0.534)\end{array}$ \\
\hline Japan & $\begin{array}{c}-2.339 * * * \\
(0.719)\end{array}$ \\
\hline Other & $\begin{array}{c}-3.317 * * * \\
(0.837) \\
\end{array}$ \\
\hline \multicolumn{2}{|l|}{ Firm Characteristics } \\
\hline Firm top 25 & $\begin{array}{l}0.727^{*} \\
(0.434)\end{array}$ \\
\hline Firm size & $\begin{array}{c}0.911 * * * \\
(0.318)\end{array}$ \\
\hline Firm citations & $\begin{array}{l}-0.030 \\
(0.034)\end{array}$ \\
\hline Firm scope & $\begin{array}{l}-0.867 \\
(0.531)\end{array}$ \\
\hline Firm age & $\begin{array}{l}-0.009 \\
(0.008)\end{array}$ \\
\hline Observations & 87 \\
\hline Pseudo R-squared & 0.388 \\
\hline$\%$ correctly estimated & $81 \%$ \\
\hline
\end{tabular}

\section{APPENDIX 3: Inventor Selection}

There are various selection issues that arise with respect to mobile inventors: (1) A first potential selection problem is that only the best researchers move from IMEC to the focal firm. (2) A second inventor selection problem that may affect our analysis is that partners may be attracting better inventors from IMEC compared to non-partners. In this case, observing a positive effect of inventor links on citations might be due to a superior selection by partner firms, rather than partners being able to make better use of boundary crossing inventors. ${ }^{26}$ (3) Finally, for the group of inventors sent by partner firms to IMEC, the focal firm may have selected only the best researchers to send to IMEC, or for appropriation concerns, precisely not the best. We provide descriptive statistics on the differences in inventor profiles for each of these possible selection issues. Overall, we find little reason for

${ }^{26}$ Note that conditional on having controlled for firm selection into an IMEC partnership, i.e. that firms that are better can also better select inventors and become IMEC partners, any results that partner firms can better select mobile inventors than non-partners, is also an interesting result, as it suggest that because they have an institutional link, they will be able to hire better inventors. Nevertheless, as we want to assess the ability of firms to make better use of mobile inventors, we try to disentangle as much as possible the two stories. 
concern that selection of mobile inventors happened based on the quality of their patent output. An important caveat is that sample sizes are small for getting conclusive evidence.

\section{Do the best researchers leave IMEC to work at firms?}

For all inventors on IMEC co-assigned patents, we compare each mobile inventor who left IMEC to join a company to a representative sample of those who are still at IMEC at the time the mobile inventor left. For each mobile inventor who left IMEC, the control sample consists of all inventors who will not leave and who are still at IMEC at the time the respective inventor leaves. For this control group of inventors, we calculate the average number of patents, the average number of forward citations received by these patents and the average number of citations to scientific publications made by these patents, at the time the mobile inventor leaves. Subsequently, we compare the characteristics of the mobile inventors to the average of the matched control group of inventors. The descriptive analysis in the table below shows that those who leave are significantly more prolific, i.e. have more patents. Yet, and more important for our analysis, their average patent is not more valuable at the time they leave, as reflected by the average forward citations per patent. There are also no significant differences in the science intensity of their patents.

\begin{tabular}{|l|l|l|l|l|l|l|l|}
\hline & \multicolumn{3}{|l|}{ Mobile inventor } & \multicolumn{3}{l|}{ Matched control group } & \multicolumn{2}{l|}{} \\
\hline Variable & $\mathrm{n}$ & Mean & Std. Dev. & Mean & Std. Dev. & $|\mathrm{t}|$ & $\operatorname{Pr}(|\mathrm{T}|>|\mathrm{t}|)$ \\
\hline Number of patents & 57 & 8.84 & 9.38 & 3.50 & 5.28 & 4.94 & 0.000 \\
Forward citations & 57 & 6.72 & 7.29 & 7.03 & 6.17 & 0.27 & 0.787 \\
Science citations & 57 & 1.53 & 3.52 & 1.66 & 0.83 & 0.31 & 0.758 \\
\hline
\end{tabular}

\section{Do partners attract better IMEC researchers compared to non-partners?}

To check whether partner firms attract better researchers from IMEC compared to non-partner firms, we compare those mobile inventors that go to a partner firm with those that go to a non-partner firm at the moment when they are mobile. The analysis in the table below shows that mobile inventors that go to partner firms are more prolific, i.e. have more patents, but more important for our analysis, their average patent is not more valuable, rather less valuable at the time they leave. Moreover, their average patent has a slightly higher science intensity. However, none of the differences are significant, potentially due to the small number of observations.

\begin{tabular}{|l|l|l|l|l|l|l|l|l|}
\hline & \multicolumn{3}{|l|}{$\begin{array}{l}\text { Mobile inventors } \\
\text { partner }\end{array}$} & \multicolumn{3}{l|}{$\begin{array}{l}\text { Mobile inventors } \\
\text { non-partner }\end{array}$} & \multicolumn{2}{l|}{} \\
\hline Variable & $\mathrm{n}$ & Mean & Std. Dev. & $\mathrm{n}$ & Mean & Std. Dev. & $|\mathrm{t}|$ & $\operatorname{Pr}(|\mathrm{T}|>|\mathrm{t}|)$ \\
\hline Number of patents & 48 & 9.34 & 9.86 & 9 & 5.11 & 5.40 & 1.25 & 0.217 \\
Forward citations & 48 & 6.08 & 7.09 & 9 & 7.97 & 8.35 & 0.72 & 0.477 \\
Science citations & 48 & 1.34 & 3.48 & 9 & 1.08 & 1.38 & 0.21 & 0.833 \\
\hline
\end{tabular}

\section{Do partner firms send their best researchers as resident to IMEC?}

Finally, there might be an inventor selection issue in case partner firms would send their more competent researchers to IMEC. From interviews with managers from IMEC we learned that this is 
not necessarily the case because companies do not want to share their most valuable human resources with other firms, including competitors. At the same time, they have to ensure that the participating researchers are able of identifying, absorbing and integrating relevant knowledge. IMEC controls this selection behavior by providing partners with quarterly evaluations of their researchers working at IMEC. We attempt to check this inventor selection issue more formally by matching IMEC-visiting partner researchers in our sample prior to their visits with a group of comparable inventors working for the same firm. We match each mobile inventor with each of its co-inventors on patents assigned to the same partner firm before his/her IMEC visit and exclude co-inventors which went to IMEC in the past or went to IMEC in the post-sample period. We calculate the number of patents, the average number of forward citations received, and the average number of science citations made for each inventor before his/her IMEC visit and compare this to the average co-inventor at the same point in time. We only had a small sample of 23 inventors (and 182 matching co-inventors) for which we could perform such analysis but results obtained from $\mathrm{T}$-tests indicate that the partner researchers going to IMEC are not significantly different from other researchers working for the same company on similar types of $R \& D$ projects, suggesting that there is no obvious inventor selection issue.

\begin{tabular}{|l|l|l|l|l|l|l|l|l|}
\hline & \multicolumn{2}{|l|}{ Mobile inventors } & \multicolumn{2}{l|}{ Matched control group } & \multicolumn{2}{l|}{} \\
\hline Variable & $\mathrm{n}$ & Mean & Std. Dev. & $\mathrm{n}$ & Mean & Std. Dev. & $|\mathrm{t}|$ & $\operatorname{Pr}(|\mathrm{T}|>|\mathrm{t}|)$ \\
\hline Number of patents & 23 & 9.13 & 9.50 & 23 & 8.95 & 8.62 & 0.0669 & 0.947 \\
Forward citations & 23 & 5.90 & 5.56 & 23 & 6.33 & 6.42 & 0.3349 & 0.741 \\
Science citations & 23 & 0.61 & 1.49 & 23 & 0.40 & 1.21 & 0.8147 & 0.424 \\
\hline
\end{tabular}

